NBER WORKING PAPER SERIES

\title{
KNOWLEDGE CREATION AND CONTROL IN ORGANIZATIONS
}

\author{
Diego Puga \\ Daniel Trefler \\ Working Paper 9121 \\ http://www.nber.org/papers/w9121 \\ NATIONAL BUREAU OF ECONOMIC RESEARCH \\ 1050 Massachusetts Avenue \\ Cambridge, MA 02138 \\ September 2002
}

The views expressed herein are those of the authors and not necessarily those of the National Bureau of Economic Research.

(C) 2002 by Diego Puga and Daniel Trefler. All rights reserved. Short sections of text, not to exceed two paragraphs, may be quoted without explicit permission provided that full credit, including $\odot$ notice, is given to the source. 
Knowledge Creation and Control in Organizations

Diego Puga and Daniel Trefler

NBER Working Paper No. 9121

September 2002

JEL No. O31, L22, D23

\begin{abstract}
$\underline{\text { ABSTRACT }}$
The incremental innovations that underly much of modern economic growth typically involve changes to one or more components of a complex product. This creates a tension. On the one hand, a principal would like an agent to contribute innovative components. On the other hand, ironing out incompatibilities between interdependent components can be a drain on the principal's energies. The principal can conserve her energies by tightly controlling the innovation process, but this may inadvertently stifle the agent's incentive to innovate. We show precisely how this tension between creating knowledge and controlling knowledge shapes organizational forms. The novel concepts introduced are illustrated with case studies of the flat panel cathode ray tube industry and Boeing's recent location decisions.
\end{abstract}

Diego Puga

Department of Economics

University of Toronto

150 Saint George Street

Toronto, Ontario M5S 3G7

Canada

and NBER

d.puga@utoronto.ca

http://dpuga.economics.utoronto.ca
Daniel Trefler

Department of Economics

University of Toronto

150 Saint George Street

Toronto, Ontario M5S 3G7

Canada

and NBER

trefler@chass.utoronto.ca 
Who creates knowledge and who controls it? These are among the most familiar questions of our age. The myriad issues at stake are brought home by the intensity of recent debates about the scope of patent policy, by the household familiarity with corporate names such as Microsoft and Celera Genomics (giants in the field of knowledge creation and control), and by the technology-based economic resurgence of the United States. In an international context, the location of knowledge creation and control has additional political and economic implications. In developing countries, there is a sense that rich countries have failed to create knowledge that is appropriate to local needs. In middle- and even some high-income countries, there is a sense of impinged sovereignty because knowledge is often controlled by the headquarter operations of foreign multinationals. Often implicit in these discussions is an assumption that knowledge-based externalities are large and that one cannot control knowledge without creating it.

Yet knowledge creation and control are not just about grand new technologies. They are equally about incremental technological progress. Rosenberg's (1982a) unsung hero of modern economic growth is the mundane day-to-day of incremental innovation. This is partly captured by such phrases as Arrow's (1962a) 'learning by doing' and Rosenberg's (1982b) 'learning by using'. One finds incremental innovation not among lab-coated technicians, but in business enterprises with their focus on cost-cutting process improvements, quality control, and minor product innovations. Yet if incremental innovation is so important then a large piece of the economic puzzle is missing. Absent is a positive theory of the incentives a firm uses to induce incremental innovation on the part of its employees and subcontractors. Restated, we do not understand the role of incremental innovation for the internal organization of the firm.

Our analysis of these incentives leads us to a theory of organizational forms built on three elements. The first, emphasized by Arrow (1962b) in his seminal work on knowledge markets, is that there is an inherent uncertainty surrounding knowledge creation. This so limits the contracting environment that it is appropriate to assume that contracts are incomplete. When products are standardized and production processes routine, it 
is easy for the firm to write detailed contracts governing its relations with employees and subcontractors. However, as Sabel (1994) pointed out, innovation undermines the very foundations of such contracts precisely because knowledge creation is about altering products and processes in potentially unpredictable ways.

The second element, also emphasized by Arrow (1962b), is that knowledge is inherently a public good and hence non-appropriable. Thus, to the extent that a principal engages an agent (be it an employee or a subcontractor) in active knowledge creation, there is the potential for the agent to walk away with the jointly created knowledge. This problem is particularly severe in the context of incremental innovations, which are more and more often the result of collaborative efforts such as concurrent engineering between firms and their sub-contractors (Helper, MacDuffie, and Sabel, 2000).

The third and final element of our paper flows from the fact that incremental innovation is often embedded in complex, interdependent systems in which an incremental improvement in one component is not effective unless other components are also modified. In the simplest case, when a firm asks a parts supplier to improve a component, the solution may entail residual incompatibilities with other components of the system, thus forcing the firm to incur the additional expenses associated with bringing other components into line. This interdependence sets up the possibility that the parts supplier may not internalize all of the firm's innovation costs. We model this using the novel concept of the imperfect substitutability of innovative effort. Imperfect substitutability is a measure of the costs imposed on one party (the principal or agent) by the innovative efforts of the other party (the agent or principal).

Consider two examples that highlight different aspects of the imperfect substitutability of innovative efforts. The first example deals with differences between the technical competencies of the principal and the agent. Florescent lighting systems consist of a ballast and a lamp. The ballast passes a charge through the electrodes at each end of the lamp. This charge excites the gas in the lamp which in turn makes the lamp's phosphor coating glow. While seemingly simple, this system has been subject to countless incremental 
changes over the last 40 years. What makes these changes complicated is the interaction between the ballast on the one hand and the lamp components (electrodes, gas, and phosphor) on the other. For instance, changes in the ballast that improve energy efficiency typically stress the electrodes, causing delays and flickering on start-up, darkening of the lamp ends, changes in the colour spectrum, and reduced lamp life. ${ }^{1}$ Consider a North American lamp manufacturer who wants to enter European markets. Since we have not yet introduced any elements that distinguish the principal from the agent, we arbitrarily refer to the lamp manufacturer as the principal. Europeans are tolerant of start-up delays, but not of energy inefficiency. As a result, the principal engages a European ballast manufacturer (the agent) to help improve energy efficiency. The principal's technical competence will incline her towards a solution or blueprint that alters the lamp components in a way that fails to fully recognize how difficult it will be for the agent to produce a compatible ballast. That is, the principal's blueprint will tend to be costly for the agent to implement. Likewise, the agent's technical competence will incline him towards a modification of the ballast that does not fully recognize the lamp-compatibility complications this imposes on the principal.

The next example has all the elements of complex, interdependent systems that were featured in the previous example. In addition, the next example introduces an incentive problem. The agent develops a number of alternative solutions to an incremental innovation problem, but only reports the solution that is easiest for him to implement (as opposed to the solution that is easiest for the principal to implement). Faced with stability problems in the Ford Explorer sports utility vehicle shortly before its scheduled production date of 1990, Ford engineers considered four alternative solutions: widening the chassis, lowering the engine, fitting smaller tires, or lowering the tire pressure. Ford chose the latter fix and recommended a tire pressure well below that suggested by its tire supplier, Firestone. This worsened fuel economy so that in 1994, Ford instructed Firestone to redesign the tire with the aim of making it lighter. This was not trivial: Ford wanted an innovative tire

\footnotetext{
${ }^{1}$ See National Lighting Product Information Program (1994) and United States Environmental Protection Agency (1998).
} 
that looked like a truck tire, but handled like a car tire. In 2001, following increasingly frequent rollover accidents due to tire blowouts, Ford recalled 13 million Firestone tires. In the much-publicized legal battle that followed, each side insisted that the problem lay with the other company. Ford claimed that the specific choices made by Firestone in redesigning the tires were to blame and accused Firestone of concealing the associated risks. Firestone blamed Ford for withholding information about increases to the vehicle weight that reduced tire safety margins and contended that Ford should have addressed the vehicle's stability problems directly. At the various knowledge-creation stages of this process, each party offered a 'blueprint' that shifted the implementation costs onto the other. $^{2}$

In these examples, there is an incremental innovation that is embedded in a complex or interdependent system in which alterations in one component affect the performance of other components. In this environment there are many layers of uncertainty, including uncertainty about the appropriate performance targets for each separate component. Substitutability measures the extent to which the full costs of innovation, including residual incompatibilities to be resolved by the other party, are internalized by the innovator. If the residual incompatibilities are important then we say that the innovative efforts of the principal and agent are only 'imperfectly substitutable'.

Once we acknowledge that the innovative efforts of the principal and the agent are imperfectly substitutable, it becomes crucial to know who will have the final say or control over which innovation is implemented in the event that both parties independently innovate successfully. In this situation, where there are two solutions on the table, each party prefers ex post control because it shifts the cost of eliminating residual incompatibilities onto the other party. Thus, as in Aghion and Tirole (1997), control can be used ex ante as an incentive device to induce innovative effort. (As we shall see, our notion of substitutability is a development of Aghion and Tirole's (1997) notion of congruence.) If the agent has control, he has a greater incentive to innovate so as to shift residual

\footnotetext{
${ }^{2}$ See http://www.safetyforum.com/firestone/ and http://www.time.com/time/business/article/ $0,8599,128198,00 \cdot \mathrm{html}$.
} 
incompatibility costs onto the principal. Thus, the degree of substitutability is crucial for thinking about who creates knowledge and who controls it. Provided that substitutability is sufficiently high (residual incompatibilities are sufficiently small), the principal has an incentive to engage an agent in knowledge creation and perhaps even to delegate to the agent control over how knowledge is used. This reduces the busy principal's time spent on innovation without unduly increasing time spent on residual incompatibilities. In hiring the agent, the principal might commiserate with Irving Berlin ("anything you can do, I can do better"), but will take heed of Ricardo's advice by having the agent participate in knowledge creation.

The degree of appropriability is also a determinant of organizational forms. Provided the risk of appropriability is low, the principal will have an incentive to engage the agent in knowledge creation. While this last point is not new (see, e.g., Markusen, 2001), it is worth noting that our notion of appropriability, which is based on the public-goods nature of information, differs from the hold-up problem described in Klein, Crawford, and Alchian (1978), Williamson (1985), Hart (1995), and others. Also, we will document some interesting interactions between appropriability and substitutability that are relevant for thinking about organizational forms.

We believe that the three core elements of our framework - contractual incompleteness, non-appropriability, and imperfect substitutability - are uniquely important in the context of day-to-day incremental innovation. The incremental nature of innovation means that the benefits of a contract governing the increment alone are small. Further, since incremental improvements to components of an interdependent system almost always involve collaborative efforts, often in hierarchical settings, the non-appropriability of knowledge and the imperfect substitutability of innovative efforts are crucial concerns.

As the paper unfolds we will provide a large number of detailed examples drawn from manufacturing. Each of these examples involves puzzles that cannot be understood within existing frameworks. For example, why is Sony one of the few integrated TV manufacturers and why did that integration only come in 1997? For another, why did 
Boeing go to great lengths in order to separate its headquarters from all of its production facilities and why did Boeing simultaneously promote its business unit managers within the organizational hierarchy? We will argue that these and other industrial organization questions can only be answered by reference to notions of appropriability and especially substitutability, that is, by reference to what it is that determines who creates knowledge and who controls it.

The paper is organized as follows. Section 1 sets up the model. Section 2 describes three organizational forms that come out of our model and that differ in terms of who controls and who creates knowledge. Section 3 shows how organizational forms affect the incentives to produce knowledge and sections $4-7$ describe how substitutability and appropriability determine the choice of organizational form. Section 8 embeds the analysis of a single principal and a single agent into a general equilibrium model in which the number of principals and agents is endogenous as are their outside options. Section 9 concludes.

\section{Set-up}

We have in mind a situation in which a firm with an existing product sets out to improve it with an incremental process or product innovation. We use the term innovation in its broadest sense to include, for example, a marketing innovation. We model this situation as a principal $p$ (she) who engages an agent $a$ (he) to help her develop and implement a blueprint for this incremental innovation. Both the principal and the agent are riskneutral. We now describe the sequence of events in chronological order (the subheadings in this section summarize the timeline). 


\section{A. Matching}

The principal costlessly matches with an agent whose innovative effort is broadly substitutable for her own. ${ }^{3}$ The exact degree of substitutability is not known by either party until they actually work together. That is, the principal and agent initially only know the distribution from which $s$ is drawn.

\section{B. The contracting environment}

Upon matching (but before substitutability is revealed) the pair writes a contract contingent on contractable information. Not all information in the model is contractable. Most significantly, a contract cannot be contingent on any aspect of the blueprint for the innovation. These aspects are the technical information contained in the yet-to-be-developed blueprint, whether the blueprint is workable, and who developed the blueprint in the case where both parties contributed innovative effort. The contractual incompleteness is motivated by the uncertainties associated with knowledge creation in settings where innovation involves the incremental improvement of a component part of an interdependent system. The parties cannot contract on the blueprint that will eventually be developed since, by definition, the blueprint is new knowledge and therefore unknown to the parties at the time of writing the contract. Also, the parties cannot contract on the blueprint because, if the principal asks the agent to help her in knowledge creation, then an outside party such as a court is unable to disentangle the relative contribution of each party's innovative effort to the final blueprint. Also, as is standard, effort is neither observable nor contractable. ${ }^{4}$

${ }^{3}$ The assumption that matching is costless is innocuous. For one, matching costs may be modelled as a fixed cost that has no marginal implications once a principal and agent are matched. It will have general equilibrium implications, but these are not complicated. For another, costly matching adds nothing to the analysis that has not otherwise been examined in the context of organizations (e.g., by McLaren, 200o; Grossman and Helpman, 2002; Helsley and Strange, 2002). It is therefore an unnecessary complication.

${ }^{4}$ Note that we are asserting rather than proving that contractual incompleteness flows from the context of the problem. For a foundational analysis of incomplete contracts see for example the debate involving Maskin and Tirole (1999), Hart and Moore (1999) and Segal (1999). See also Anderlini and Felli (1994). 
This leaves only four pieces of information upon which to contract. These are (1) whether the agent is involved in knowledge creation, (2) whether, when multiple blueprints are developed, the principal retains or delegates control over which blueprint to implement, (3) whether production occurs, and (4) whether payments are made. By 'organizational form' we mean aspects of the contract that deal with knowledge creation (item 1) and knowledge control (item 2). The contract that the principal and the agent sign upon matching states the payment that the agent will receive, conditional on production, under each organizational form.

\section{Organizational choice}

After the state-contingent contract is signed the principal and the agent start working together, thus revealing the degree of substitutability of their innovative efforts. ${ }^{5}$ The principal then chooses the organizational form. There are two aspects to this choice of organizational form. First, the principal must decide whether or not to engage the agent in knowledge creation i.e., in blueprint development. Second, the principal must decide ex ante whether to retain or to delegate to the agent the choice of blueprint in the event that several blueprints are developed. The first decision is about who creates knowledge. The second is about who controls knowledge.

The principal is distinguished from the agent only by her authority to make these two decisions. The question of who has this authority typically flows naturally form the situational context (e.g., a manager can set the tasks and responsibilities of a subordinate employee while the reverse is not true). It also flows from the agent's incentive compatibility constraint. The principal can ask the agent to engage in the creation and control of knowledge, but the agent has the right to refuse. We will show that the incentive compatibility condition ensuring that the agent agrees implies that the principal must have higher income than the agent. In practice, both considerations (position within

5This sets up the potential for an interesting dynamic. The principal and agent may wish to start with smaller projects or projects with less uncertainty about $s$ and then, over time, consider more complex projects. We hope to examine this issue in future research. 
an organization and incentive compatibility) are closely related: greater authority over the allocation of tasks within an organization goes hand in hand with higher earnings. Thus, despite the symmetry between the two parties in other respects, we will show that incentive compatibility means that roles cannot be reversed.

There are two additional constraints on the contracted payments to be considered. One of these is that the payments under each organizational form must be such that both parties prefer the contract to an outside option. This option takes the form of alternative occupations that will be introduced when we turn to general equilibrium modelling. Thus, in general equilibrium the opportunities available to the principal and the agent affect the size of the contracted payments via their individual rationality constraints. An additional incentive compatibility issue is that these payments are also affected by the appropriability of knowledge: when the agent is involved in knowledge creation his payment must reflect what he and the principal expect to get if either one takes the other party to court over the knowledge created. We now develop this latter issue.

\section{Knowledge creation and appropriability}

If the principal involves the agent in knowledge creation, then there is potentially an appropriability problem. Consider two scenarios. On the tacit knowledge side, if the agent is involved in knowledge creation then he will learn key non-codifiable knowledge that cannot be incorporated into any blueprint. The principal's innovation decisions will also reveal to a closely-involved agent many details of the principal's market strategies. As a result, once involved in knowledge creation the agent will be able to exploit jointly created knowledge in a way that denigrates the principal's profits. ${ }^{6}$ On the legal side, if both parties are involved in knowledge creation then the agent may be able to make a

\footnotetext{
${ }^{6}$ One way for the principal to partially prevent non-appropriability is by means of a restrictive covenant stating that if the principal-agent relationship is terminated, the agent will not then compete directly with the principal. However, such covenants are illegal in many jurisdictions (including California, under Section 16600 of the Business and Professions Code). Even where they are legal, they are generally not enforceable unless (1) they are sufficiently limited in scope and duration (e.g., one year under Section 36 of the Austrian Employee's Act), (2) they adequately compensate the employee (e.g., Article 2125 of the Italian Civil Code), and (3) they impose limited penalties for breach of contract (e.g., a maximum of twelve month's salary in France). See Thiébart (2001).
} 
credible claim in court that he came up with the crucial ideas. It is remarkably difficult for the principal to prevent a successful court challenge, even in settings where the facts and legal issues are clear. ${ }^{7}$ A fortiori the problems are more severe in our incremental knowledge setting.

For simplicity, we model the appropriability problem as a possible court challenge. We capture this with a parameter $\lambda$ that is the probability a court awards the operational profits $\pi$ to the agent. It follows that if the agent is involved in knowledge creation then the agent must be paid $\lambda \pi$. If the agent receives less than this then the risk-neutral agent can do better by taking the case to court and receiving an expected return of $\lambda \pi$. If the agent receives more than $\lambda \pi$ then the principal receives less than $(1-\lambda) \pi$. It follows that the risk-neutral principal can do better by taking the case to court and receiving an expected return of $(1-\lambda) \pi$. It is possible that the agent gains additional tacit knowledge or credibility in court when he has control over the choice of blueprints. We allow for this possibility below by having an appropriability risk parameter $\lambda$ for the case of no control and a parameter $\lambda^{\prime}\left(\lambda^{\prime}>\lambda\right)$ for the case of control. We start with the simpler case in which $\lambda^{\prime}=\lambda{ }^{8}$

7The controversy over the discovery of streptomycin is illustrative. In 1939 microbiologist Selman Waksman discovered that soil microbes known as actinomyces produce substances that destroy other microbes. He named these substances 'antibiotics.' After developing a method to systematically search for antibiotics, he hired a team of lab assistants to implement it. This systematic search lead Waksman to the discovery of 22 antibiotics, including streptomycin which in 1944 became the first effective treatment against tuberculosis. In 1949 Albert Schatz, who had been involved in the discovery of streptomycin as a student lab assistant, successfully sued Waksman for a share of the royalties. Schatz's legal success came despite the fact that Waksman had been studying actinomyces for over 30 years, had devised the technical procedure that led to the discovery (for which he received the Nobel Prize), had hired Schatz as a salaried lab assistant, had identified many other antibiotics both before and after he met Schatz, and 28 years earlier had even isolated the actinomycete responsible for streptomycin. In contrast, Schatz had been involved in the project for just a few months prior to the discovery and had made no other major contribution to medical research. See Wainwright (1990). Even in this apparently clear-cut case, the principal was unable to prevent the agent from appropriating the knowledge created i.e., from claiming a share of the profits.

${ }^{8}$ It is worth noting how our framework differs from the standard principal-agent problem with unobserved agent effort. There, if one assumes that both actors are risk neutral (as we do here), the principal can get the agent to fully internalize the effects of his effort decision with an endogenously chosen payment scheme that depends on the effort-related outcome. However, in our setting of incremental knowledge creation, the unobservability of effort is only one component. An equally important component is that it is not possible to determine whether the agent's effort contributed to the development of the blueprint. 


\section{E. Knowledge control and substitutability}

Having decided to involve the agent in knowledge creation, the principal must also decide whether to retain control over the use of the knowledge created or to delegate control to the agent. Control is defined as the right to choose whose blueprint will be implemented in the event that the principal and the agent come up with competing specifications. As in Aghion and Tirole (1997), control is an incentive device to induce innovative effort in settings where monetary incentives are insufficient. ${ }^{9}$ Control is an effective incentive because of the imperfect substitutability of innovative efforts. Suppose that there are two alternative blueprints, one designed by the principal and the other designed by the agent. Our key assumption is that if the principal develops a blueprint for an incremental innovation, then the interdependence between components requires the agent to make some changes in response. As a result, the principal's blueprint shifts the problem of residual incompatibilities onto the agent. Likewise, the agent's blueprint shifts the problem of residual incompatibilities onto the principal. Recall that the fluorescent light and Ford-Firestone examples were intended to show that our key imperfect-substitutability assumption reflects the realities of day-to-day incremental innovation.

\section{F. Innovation}

To capture the idea of imperfect substitutability in its simplest form, innovation is modelled as a two-stage process. In the first stage an incremental innovation is developed and codified in a blueprint. This amounts to finding a solution to an incremental innovation problem. Finding such a solution requires creative effort from one and possibly both parties. In the second stage the blueprint is implemented. This amounts to adapting

\footnotetext{
9In Aghion and Tirole (1997), monetary incentives do not work because the agent is assumed to be infinitely risk-averse. In our setting, the agent is risk neutral and does respond to monetary incentives. However, the difficulty of identifying the relative contribution of each party to incremental knowledge creation raises an appropriability risk. This appropriability risk constrains what the principal pays the agent once involved in knowledge creation. On the one hand, it forces the principal to pay the agent enough that the agent gets involved in knowledge creation and does not to walk away with the knowledge gained. On the other hand, it constrains the distribution between the parties of the benefits of a successful innovation and thus limits the extent to which the principal can induce innovative effort by the agent with monetary incentives alone.
} 
existing components to the solution found. It requires implementation effort from one and possibly both parties. In practice, the distinction between the two stages is not hard and fast. The first stage typically does not provide a complete blueprint so that the second stage also involves some amount of effort that with certainty will eliminate the final bugs. ${ }^{10,11}$

Let $e_{i}(i=p, a)$ be the time $i$ spends on creative effort. Let $1-s_{i}$ be the time $i$ spends on implementation effort. We also allow for the empirically likely possibility that the knowledge gained from research helps one eliminate the final bugs in the implementation stage. Let $e_{i}\left(1-s_{i}\right)$ be the reduction in time spent on implementation effort given that time $e_{i}$ has already been spent on creative effort. Each actor is endowed with one unit of time so that leisure is given by

$$
\begin{aligned}
l_{i} & =1-\left[e_{i}+\left(1-s_{i}\right)-e_{i}\left(1-s_{i}\right)\right] \\
& =\left(1-e_{i}\right) s_{i} .
\end{aligned}
$$

This captures in the simplest terms the way in which effort translates into time. It is worth noting that, while this is a particularly convenient parameterization of how effort translates into loss of leisure time, more general parameterizations (e.g., having non-unitary coefficients in front of each of the terms $e_{i},\left(1-s_{i}\right)$, and $\left.-e_{i}\left(1-s_{i}\right)\right)$ yield qualitatively the same results. ${ }^{12}$

Indirect utility for economic actor $i(i=p, a)$ is

$$
U_{i}=\frac{y_{i} l_{i}}{P},
$$

\footnotetext{
${ }^{10}$ The main difference between creative and implementation effort is that there is much greater uncertainty regarding the outcome of creative effort. One may work hard at trying to come up with a solution to a problem without finding one. However, once a solution is found, fixing the final bugs may take more or less effort but can certainly be done.

${ }^{11}$ Notice that all inputs into the knowledge creation process are measured in terms of effort - there are no intermediate inputs or non-effort primary inputs. One could introduce intermediate inputs into the innovative process as in Duranton and Puga (2001). However, this would simply raise a series of general equilibrium interactions that are well understood and would distract us from the main focus of this paper.

${ }^{12}$ We can be precise about what we mean by 'qualitative.' Without anticipating our results too much, we basically show that there is a parameter space, say $[0,1]$, such that each organizational form lives uniquely on an interval $\left(\alpha_{j}, \alpha_{j+1}\right)$ in $[0,1]$. The choice of functional form does not affect the existence of organizational forms nor the ordinal ranking of the $\alpha_{j}$. It only affects the cardinal values of the $\alpha_{j}$. (We do not use this cardinal information.) This is what we mean throughout the paper when we mention that much more general specifications yield qualitatively the same results.
} 
where $y_{i}$ is $i$ 's income and $P$ is the relevant price index, which we will take as numéraire. Thus, preferences over goods are homothetic and the utility derived from purchased goods is proportional to the leisure time one has to enjoy those goods. ${ }^{13}$.

Creative effort by $i(i=p, a)$ translates into one or more blueprints with probability $e_{i}$ and into no blueprint with probability $1-e_{i} \cdot{ }^{14}$ All blueprints yield the same total profit or real income so that they are distinguished only by the amount of effort required from each party to implement them.

Suppose that the principal has developed at least one blueprint. Then the principal's preferred blueprint from among the set of all blueprints she has developed will be the one with the smallest implementation costs for her. We assume that the implementation costs of the principal's preferred blueprint are higher for the agent than for the principal. Likewise for the blueprint that the agent prefers from among the set of blueprints he has developed: implementation costs of the agent's preferred blueprint are higher for the principal than for the agent. To formalize this, without loss of generality we normalize implementation effort required by $i$ to implement $i$ 's own blueprint by setting it to 0 . In addition, we simplify by setting $i^{\prime}$ s implementation effort equal to $\left(1-e_{i}\right)(1-s)$ for the case where $i$ is implementing $j^{\prime}$ s blueprint $(i \neq j)$. That is, we assume that it is equally difficult for the agent and for the principal to implement each other's blueprint and that the required implementation effort is decreasing in the match-specific parameter s. Given this parameterization, $s$ is a measure of the degree of substitutability of creative efforts. The larger is $s$, the more substitutable is creative effort. Under this parameterization our notion

\footnotetext{
${ }^{13}$ For instance, the principal may use her income to buy a fancy mansion, season opera tickets, or a Ferrari. If she chooses to work very hard, putting lots of effort into developing and implementing a blueprint, she will spend many evenings and weekends in the office. As a result, she will have little chance to enjoy her mansion, will frequently miss operas, and the Ferrari will mostly gather dust in the garage. Note that this specific choice of preferences is not important for our qualitative results. What matters is that preferences are weakly separable so that we can study decisions regarding effort by the principal and the agent independently of their consumption choices.

${ }^{14}$ Note that $i$ 's probability of success is independent of $j$ 's creative effort. This is not important. We could also assume that $i$ 's probability of success increases with $j$ 's creative effort, as long as this type of complementarity does not dominate our core notion of imperfectly substitutable creative efforts. We can easily make this statement about dominance precise, but there is little point in doing so because the focus of our paper is on incremental knowledge creation and not on the sort of high-tech research in which complementarities are important.
} 


\begin{tabular}{lccc}
\hline \hline Organizational form & Short name & Agent creates knowledge & Agent controls knowledge \\
\hline Implementation form & I form & No $\left(e_{a}=0\right)$ & No \\
Knowledge form & K form & Yes $\left(e_{a}>0\right)$ & No \\
Control form & C form & Yes $\left(e_{a}>0\right)$ & Yes \\
\hline
\end{tabular}

Note: In all 3 forms, the principal creates knowledge $\left(e_{p}>0\right)$.

Table 1. The three organizational forms

that each party's preferred blueprint shifts the implementation effort to the other party is simply $0<\left(1-e_{i}\right)(1-s)$, or equivalently, $s<1$. It follows from this parameterization that $i$ 's leisure is

$$
l_{i}= \begin{cases}\left(1-e_{i}\right) & \text { if } i^{\prime} \text { 's blueprint is implemented } \\ \left(1-e_{i}\right) s & \text { if } j^{\prime} \text { s blueprint is implemented }\end{cases}
$$

For strictly positive leisure, we require $s>0$. In combination with the previous restriction, this implies that $s \in(0,1)$.

\section{G. Production}

Whenever a blueprint is created and implemented, production takes place and operational profits are used to make the payments specified in the contract. If no blueprint is created, then there is no production. Given that all blueprints are equally profitable, we can study the choice of organizational form separately from production decisions. Thus, we leave the specification of production decisions for the penultimate section.

\section{Organizational forms}

Variations in the degree of substitutability and appropriability generate three distinct organizational forms that are distinguished by whether the agent is involved in knowledge creation and, if so, whether the agent has control over knowledge. Table 1 provides a schematic. We now review these organizational forms in detail. 


\section{A. The implementation-form organization (I form)}

In the implementation form organization ('I form' for short), the principal does not engage the agent in knowledge creation i.e., $e_{a}=0$. Rather, the principal develops the blueprint and has it implemented by the agent (i.e., the agent sorts out the final bugs). Conditional on production the principal pays the agent some amount $w_{a}^{I}$ and is left with $\pi-w_{a}^{I}$. The level of operational profits $\pi$ and its division between $w_{a}^{I}$ and $\pi-w_{a}^{I}$ are endogenized in the penultimate section where we introduce the free-entry conditions for principals and agents. The principal's problem is to choose a level of creative effort $e_{p}$ that maximizes her expected utility:

$$
\max _{\left\{e_{p}\right\}} \mathbf{E} U_{p}^{I} \quad \text { where } \quad \mathbf{E} U_{p}^{I}=\left(\pi-w_{a}^{I}\right) e_{p}\left(1-e_{p}\right) .
$$

The principal develops a blueprint with probability $e_{p}$ and, since it is her blueprint, all implementation costs are borne by the agent. Thus, the principal's leisure is $1-e_{p}$ and the agent's leisure is $\left(1-e_{a}\right) s=s$. Correspondingly, the expected utility for the agent is

$$
\mathbf{E} U_{a}^{I}=w_{a}^{I} e_{p} s .
$$

If no blueprint is developed, which happens with probability $1-e_{p}$, there is no production and income levels are zero. This raises two issues that apply to all organizational forms. First, we are presuming that production is always preferred to no production. This follows from and is the purpose of our assumption that $s>0$. Second, it would be of interest to introduce a fixed production cost that must be incurred independent of the outcome of research e.g., a factory must be built or the agent must be compensated even if there is no production. However, this fixed cost does not alter our conclusions and only adds another parameter to keep track of. We therefore assume that there are no fixed costs other than the blueprint requirement itself.

The solution to $(5)$ is trivial $\left(e_{p}=1 / 2\right)$. For future reference, denote the equilibrium creative effort levels under the I form by

$$
e_{p}^{I}=1 / 2 \quad \text { and } \quad e_{a}^{I}=0 .
$$




\section{B. The knowledge-form organization (K form)}

In the knowledge-form organization ('K form' for short), the principal engages the agent in knowledge creation $\left(e_{a}>0\right)$, but retains control over the choice of blueprints. Involving the agent in knowledge creation leads to a risk of appropriability which, as discussed above, leaves the agent with income $\lambda \pi$ and the principal with income $(1-\lambda) \pi$. In the event that both parties come up with a blueprint, the principal will choose to have her own blueprint implemented. This shifts the implementation costs onto the agent.

The principal chooses a level of creative effort that maximizes her expected utility:

$$
\begin{aligned}
\max _{\left\{e_{p}\right\}} \mathbf{E} U_{p}^{K} \quad \text { where } \quad \mathbf{E} U_{p}^{K} & =e_{p}(1-\lambda) \pi\left(1-e_{p}\right)+\left(1-e_{p}\right) e_{a}(1-\lambda) \pi\left(1-e_{p}\right) s \\
& =(1-\lambda) \pi\left[e_{p}+\left(1-e_{p}\right) e_{a} s\right]\left(1-e_{p}\right) .
\end{aligned}
$$

That is, with probability $e_{p}$ the principal develops a blueprint, receives income $(1-\lambda) \pi$ and has leisure time of $1-e_{p}$. With probability $\left(1-e_{p}\right) e_{a}$ the principal fails to develop a blueprint, but the agent succeeds, thus leaving the principal with income $(1-\lambda) \pi$ and leisure $\left(1-e_{p}\right) s . s<1$ captures the cost to the principal of implementing the agent's blueprint. Correspondingly, the agent chooses a level of creative effort that maximizes her expected utility:

$$
\max _{\left\{e_{a}\right\}} \mathbf{E} U_{a}^{K} \quad \text { where } \quad \mathbf{E} U_{a}^{K}=\lambda \pi\left[e_{p} s+\left(1-e_{p}\right) e_{a}\right]\left(1-e_{a}\right) .
$$

The reaction functions of the principal and the agent under the $\mathrm{K}$ form are given by

$$
e_{p}^{K}\left(e_{a}\right)=\frac{1-2 s e_{a}}{2\left(1-s e_{a}\right)} \quad \text { and } \quad e_{a}^{K}\left(e_{p}\right)=\frac{1-(1+s) e_{p}}{2\left(1-e_{p}\right)} .
$$

Solving these yields the equilibrium levels of creative effort for the principal and agent:

$$
e_{p}^{K}=\frac{1}{2+s} \quad \text { and } \quad e_{a}^{K}=\frac{1}{2(1+s)} .
$$

\section{The control-form organization (C form)}

In the control-form organization (' $\mathrm{C}$ form' for short), the principal engages the agent in knowledge creation and delegates control over the choice of blueprints to the agent. It 
follows from the discussion of the $\mathrm{K}$ form that if the agent develops a blueprint, it is the agent's blueprint that is used. The problem faced by the principal is thus

$$
\max _{\left\{e_{p}\right\}} \mathbf{E} U_{p}^{C} \quad \text { where } \quad \mathbf{E} U_{p}^{C}=(1-\lambda) \pi\left[e_{a} s+\left(1-e_{a}\right) e_{p}\right]\left(1-e_{p}\right)
$$

and the problem faced by the agent is

$$
\max _{\left\{e_{a}\right\}} \mathbf{E} U_{a}^{C} \quad \text { where } \quad \mathbf{E} U_{a}^{C}=\lambda \pi\left[e_{a}+\left(1-e_{a}\right) e_{p} s\right]\left(1-e_{a}\right)
$$

The reaction functions of the principal and the agent under the $C$ form are given by

$$
e_{p}^{C}\left(e_{a}\right)=\frac{1-(1+s) e_{a}}{2\left(1-e_{a}\right)} \quad \text { and } \quad e_{a}^{C}\left(e_{p}\right)=\frac{1-2 s e_{p}}{2\left(1-s e_{p}\right)} .
$$

Solving these yields the equilibrium levels of creative effort for the principal and the agent:

$$
e_{p}^{C}=\frac{1}{2(1+s)} \quad \text { and } \quad e_{a}^{C}=\frac{1}{2+s} .
$$

We next turn to investigating how the levels of creative effort depend on the degree of substitutability $s$ and the organizational form.

\section{The role of control}

The choice of organizational form by the principal affects the extent of knowledge creation (creative effort) by both the principal and the agent. Comparison of equations (7), (11), and (15) yields the following relationship between creative effort levels and organizational forms.

\section{Lemma I (Creative effort and organizational form)}

$e_{a}^{C}>e_{a}^{K}>e_{a}^{I}=0$ and $0<e_{p}^{C}<e_{p}^{K}<e_{p}^{I}$

As we move from the I form through the $\mathrm{K}$ form to the $\mathrm{C}$ form, the principal's creative effort falls and the agent's creative effort rises. That is, the principal replaces her creative effort with that of the agent's.

Figure 1 illustrates lemma 1 by plotting the K-form and C-form reaction functions (equations 10 and 14) as well as the equilibrium creative effort levels of the principal and 


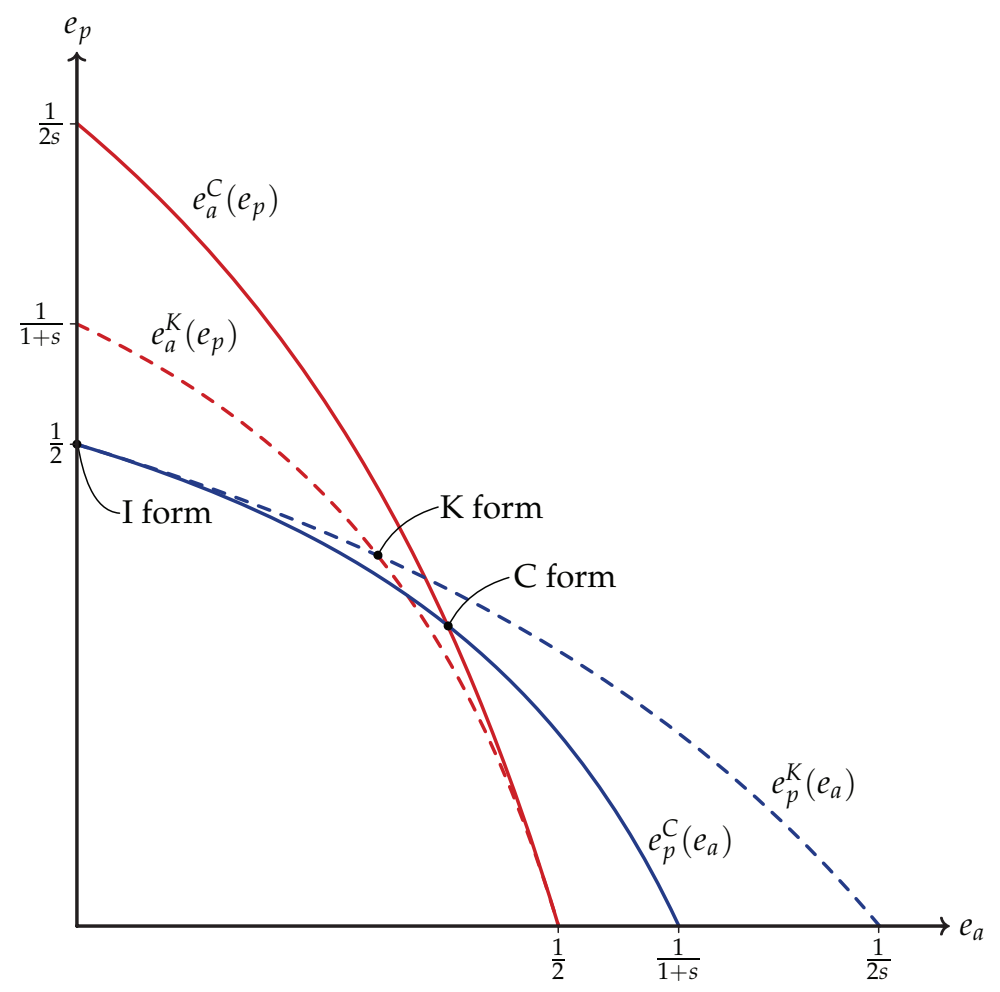

Figure 1. Creative effort reaction functions

agent (equations 7,11 , and 15). Under the I form, the agent is not involved in knowledge creation $\left(e_{a}^{I}=0\right)$ and the principal must exert a high level of creative effort $\left(e_{p}^{I}=1 / 2\right)$. Under the $\mathrm{K}$ form, the agent does some of the blueprint development $\left(e_{a}^{K}>0\right)$, thus allowing the principal to cut back on her creative effort levels. Under the $C$ form, the principal uses even more of the agent's creative effort as a substitute for her own. Why does delegating control induce the agent to exert more creative effort? Having control allows one to choose one's own blueprint, thereby shifting the burden of implementation onto the other party. This raises the returns to successfully developing a blueprint. In particular, when control is shifted from the principal to the agent the returns to creative effort rise for the agent and fall for the principal. As a result, the principal is able to replace her own creative effort with that of the agent's. Note that this central insight regarding the role of control in inducing effort first appeared in Aghion and Tirole (1997).

The analysis of lemma 1 holds $s$ fixed. We may also inquire as to the effects of our key substitutability parameter $s$ on the choice of effort. 


\section{Lemma 2 (Creative effort and substitutability $s$ )}

$$
\frac{d e_{i}^{C}}{d s}<0, \quad \frac{d e_{i}^{K}}{d s}<0, \quad \text { and } \quad \frac{d e_{i}^{I}}{d s}=0 \quad i=p, a
$$

The less substitutable is creative effort (i.e., the smaller is $s$ ), the greater is the downside risk of having to implement the other party's blueprint. This induces greater creative effort by both parties. Lemmas 1-2 are interesting features of equilibrium creative effort that feed into our main results about the choice of organizational form.

\section{The organizational choice}

The principal chooses the organizational form that yields the highest utility, subject to the agent's participation constraint. Plugging in the Nash effort levels of equations (7), (11) and (15) into the principal's expected utility functions of equations (5), (8) and (12) yields the following values for expected utility (with expectation taken over the probability of developing a blueprint):

$$
\begin{aligned}
& \mathbf{E} U_{p}^{I}=\left(\pi-w_{a}^{I}\right) \frac{1}{4}, \\
& \mathbf{E} U_{p}^{K}=(1-\lambda) \pi \frac{1+s}{2(2+s)},
\end{aligned}
$$

and

$$
\mathbf{E} U_{p}^{C}=(1-\lambda) \pi \frac{(1+2 s)^{2}}{4(1+s)(2+s)}
$$

It is mathematically convenient to re-write these equations by dividing through by $\frac{(1-\lambda) \pi}{4}$. Denoting the result by $V_{p}^{j} \equiv \frac{4}{(1-\lambda) \pi} \mathbf{E} U_{p}^{j}(j=I, K, C)$ yields:

$$
\begin{aligned}
V_{p}^{I} & =\alpha, \\
V_{p}^{K} & =\frac{2(1+s)}{(2+s)},
\end{aligned}
$$

and

$$
V_{p}^{C}=\frac{(1+2 s)^{2}}{(1+s)(2+s)}
$$

where 


$$
\alpha \equiv \frac{\pi-w_{a}^{I}}{(1-\lambda) \pi}
$$

$\alpha$ is the principal's income when the agent is not involved in knowledge creation divided by the principal's income when the agent is involved in knowledge creation. $\alpha$ thus measures the monetary cost of appropriability risk for the principal. (We use $\alpha$ for appropriability). Inspection of equation (17) makes it clear that the principal's choice of organizational form depends on just two key parameters, substitutability $s$ and appropriability $\alpha$.

Figure 2 plots the $V_{p}^{j}$ against $s$ and $\alpha$. Within a panel, the $V_{p}^{j}$ are plotted against the $s$. Across panels, the $V_{p}^{j}$ are plotted against the $\alpha$ in the sense that $\alpha$ rises as one moves from case 1 through to case 3. Consider the upper panel. The $V_{p}^{K}$ and $V_{p}^{C}$ curves are upward sloping and intersect only once. The intersection occurs at $s_{2}$. To the left of $s_{2}$ the $\mathrm{K}$ form is preferred over the $\mathrm{C}$ form while to the right of $s_{2}$ the $\mathrm{C}$ form is preferred over the $\mathrm{K}$ form. Whether the I form is preferred depends on the value of $\alpha$. The top panel of figure 2 (case 1) illustrates the case where $\alpha$ is sufficiently small that the relevant intersection is between $V_{p}^{I}$ and $V_{p}^{K}$. This occurs at $s_{3}(\alpha)$. To the left of $s_{3}(\alpha)$ the I form is preferred. ${ }^{15}$ For somewhat larger values of $\alpha$ (case 2), the relevant intersection is between $V_{p}^{I}$ and $V_{p}^{C}$ and occurs at $s_{1}(\alpha)$. To the left of $s_{1}(\alpha)$ the I form is preferred. For very large values of $\alpha\left(\alpha>\alpha_{1}\right.$ in figure 2), $V_{p}^{I}$ lies everywhere above $V_{p}^{K}$ and $V_{p}^{C}$ so that the I form is always preferred. Figure 2 is core to the paper and illustrates how the choice of organizational form depends on our two critical parameters, the degree of substitutability (s) and the degree of appropriability $(\alpha)$.

At the risk of being pedantic, we formalize the discussion of figure 2 with a couple of definitions and a proposition. This formalization brings home just how simple is the closed-form analysis.

\footnotetext{
${ }^{15}$ We will show shortly that incentive compatibility implies $\alpha>1$ which in turn implies that $\alpha$ can never be so low as to eliminate the I form entirely.
} 
Case 1

(low $\alpha$ )

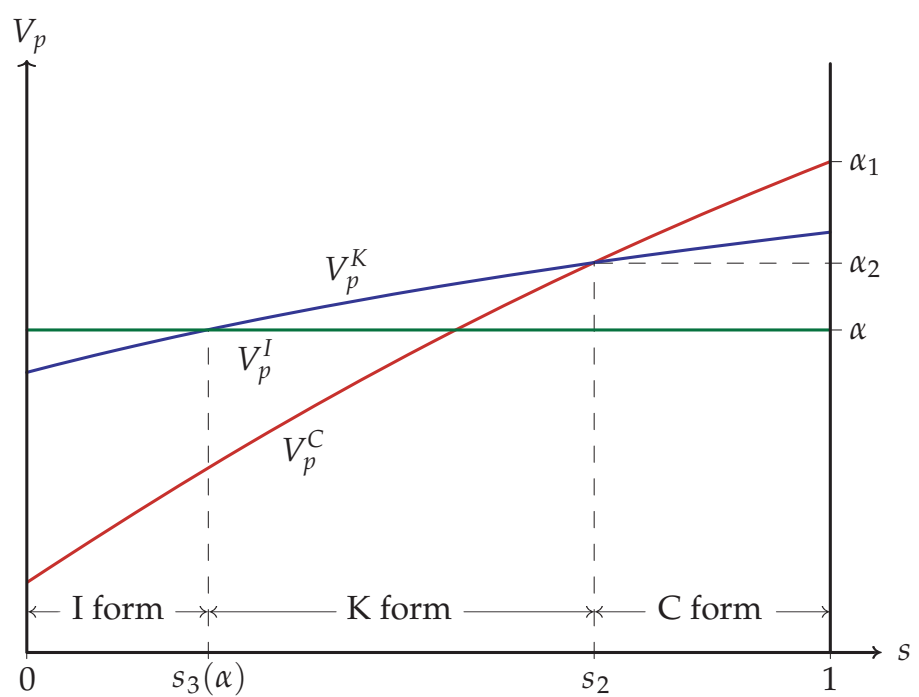

Case 2

(intermediate $\alpha$ )

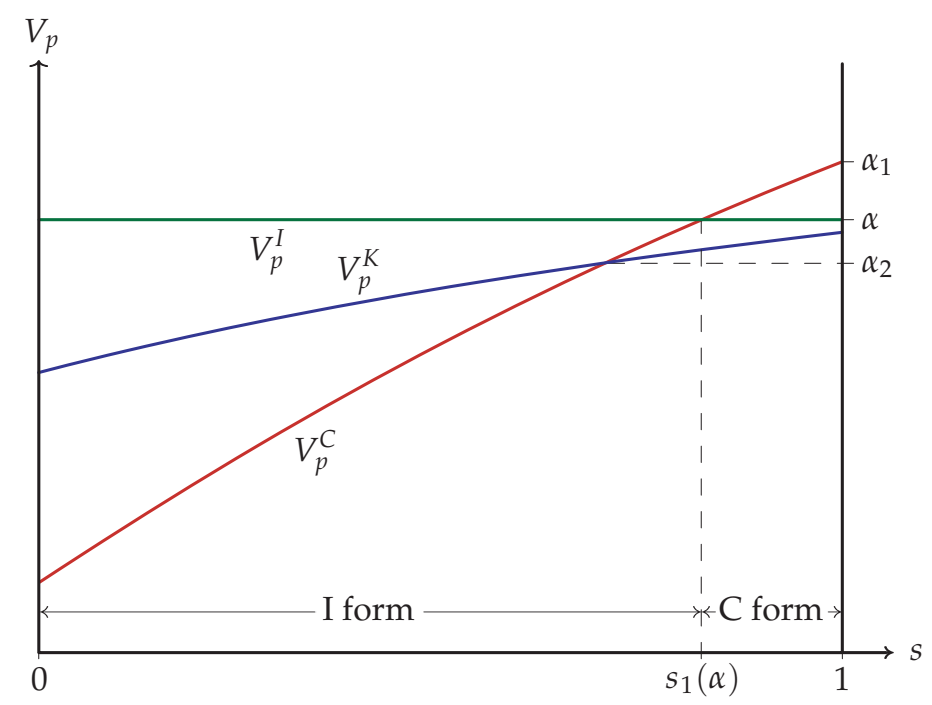

Case 3

(high $\alpha$ )

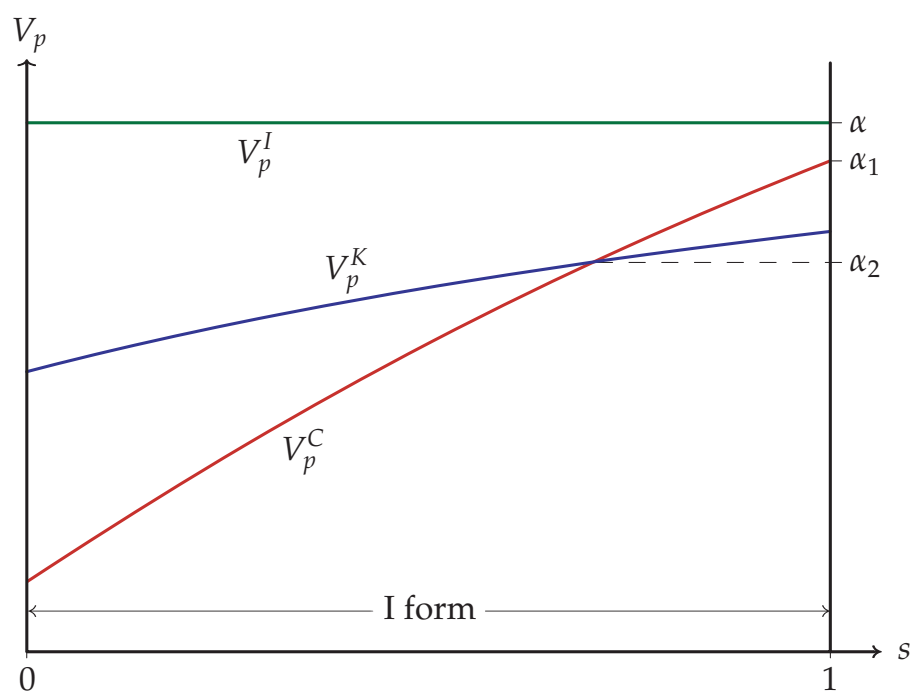

Figure 2. Determinants of organizational forms 


\section{Definition I (Critical degrees of substitutability)}

1. Let $s_{1}(\alpha) \equiv \frac{3 \alpha-4+\sqrt{\alpha(\alpha+12)}}{2(4-\alpha)}$ be the value of $s$ that equates $V_{p}^{I}=V_{p}^{C}$.

2. Let $s_{2} \equiv \frac{1}{\sqrt{2}}$ be the value of $s$ that equates $V_{p}^{K}=V_{p}^{C}$.

3. Let $s_{3}(\alpha) \equiv \frac{2(\alpha-1)}{2-\alpha}$ be the value of $s$ that equates $V_{p}^{I}=V_{p}^{K}$.

Note that $s_{2}(=1 / \sqrt{2})$ is independent of the risk of appropriation. However, as we shall see when we generalize the model, this last feature is an artifact of our simplifying assumptions rather than a robust result.

\section{Definition 2 (Critical degrees of appropriability)}

1. Let $\alpha_{1} \equiv \frac{3}{2}$ be the value of $\alpha$ that satisfies $s_{1}(\alpha)=1$.

2. Let $\alpha_{2} \equiv \frac{2+2 \sqrt{2}}{1+2 \sqrt{2}} \simeq 1.26$ be the value of $\alpha$ that satisfies $s_{2}=s_{3}(\alpha)$.

The next proposition is organized using the cases displayed in figure 2 . It is best understood by referring back to the figure.

\section{Proposition I (Determinants of organizational form)}

Case 1. If $\alpha<\alpha_{2}$ (low appropriability costs) then the principal chooses the I form whenever $s \in\left(0, s_{3}(\alpha)\right)$, the $K$ form whenever $s \in\left(s_{3}(\alpha), s_{2}\right)$, and the $C$ form whenever $s \in\left(s_{2}, 1\right)$.

Case 2. If $\alpha \in\left(\alpha_{2}, \alpha_{1}\right)$ (moderate appropriability costs) then the principal chooses the I form whenever $s \in\left(0, s_{1}(\alpha)\right)$ and the $C$ form whenever $s \in\left(s_{1}(\alpha), 1\right)$.

Case 3. If $\alpha>\alpha_{1}$ (high appropriability costs) then the principal always chooses the I form.

Proposition 1 is our core result. Before investigating the economics of this proposition let us briefly discuss incentive compatibility.

While it is the principal who offers to engage the agent in the creation and control of knowledge, the agent can always refuse. The organizational choice of proposition 1 holds provided that the agent is willing to engage in knowledge creation and control 
whenever the principal asks him to do so. That is, incentive compatibility requires that $\min \left(\mathbf{E} U_{a}^{K}, \mathbf{E} U_{a}^{C}\right)>\mathbf{E} U_{a}^{I}$ whenever $\min \left(\mathbf{E} U_{p}^{K}, \mathbf{E} U_{p}^{C}\right)>\mathbf{E} U_{p}^{I}$. A necessary and sufficient condition for this to hold for all $s$ is $w_{a}^{I} / \pi \leq 2 \lambda / 3 .^{16,17}$

The incentive compatibility constraint implies that the roles of the principal and the agent cannot be reversed despite their apparent symmetry. To see this, note that incentive compatibility is more easily satisfied the lower is $w_{a}^{I} / \pi$ because this makes involvement in knowledge creation more attractive to the agent. By involving the agent in knowledge creation, the principal is trading off income for leisure while the agent is trading off leisure for income. This will only be worthwhile for both parties if the principal is a sufficiently higher income earner in the absence of agent involvement in knowledge creation i.e., if $w_{a}^{I} / \pi$ is low. Thus, the principal is the one who wants to exchange income in return for leisure and the agent is the one who wants to exchange leisure in return for income.

\section{Organizational choice: determinants and co-existence}

There are a number of ways to interpret proposition 1. One is as a description of how substitutability $s$ and appropriability $\alpha$ determine the choice of organizational form. In this sense, the proposition offers a comparative static involving $s$ and $\alpha$. Another way to think about the proposition is as a statement about the co-existence of organizational forms. We turn to these interpretations now.

\footnotetext{
${ }^{16}$ To derive this expression, substitute equations (7), (11), and (15) into the agent's expected utility expressions of (6), (9), and (13) and compare the result with the principal's expected utilities expressions of (16). It will be immediately apparent that $\min \left(\mathbf{E} U_{a}^{K}, \mathbf{E} U_{a}^{C}\right)>\mathbf{E} U_{a}^{I}$ whenever $\min \left(\mathbf{E} U_{p}^{K}, \mathbf{E} U_{p}^{C}\right)>\mathbf{E} U_{p}^{I}$ as long as $\mathbf{E} U_{a}^{I} \leqslant \mathbf{E} U_{a}^{C}$ for $s=1$. This yields the condition $w_{a}^{I} / \pi \leq 2 \lambda / 3$.

${ }^{17}$ It is now easy to show that the intervals involving the $s_{j}(\alpha)$ in proposition 1 are well defined. In case 2, it is easy to show that $\alpha \in\left(\alpha_{2}, \alpha_{1}\right)$ implies $0<s_{1}(\alpha)<1$. Simply plug in the definitions of $\alpha_{2}, \alpha_{1}$, and $s_{1}(\alpha)$. In case 1 , it is easy to show that $s_{2}<1$ and that $\alpha<\alpha_{2}$ implies $s_{3}(\alpha)<s_{2}$. Again, plug in the definitions of $\alpha_{2}$, $s_{3}(\alpha)$, and $s_{2}$. To show $s_{3}(\alpha)>0$ note from the definition of $s_{3}(\alpha)$ and $\alpha$ that $s_{3}>0$ if and only if $\alpha>1$. But $\alpha>1$ follows from rearranging the incentive compatibility condition $w_{a}^{I} / \pi \leq 2 \lambda / 3$. Hence all the intervals in proposition 1 are well defined.
} 


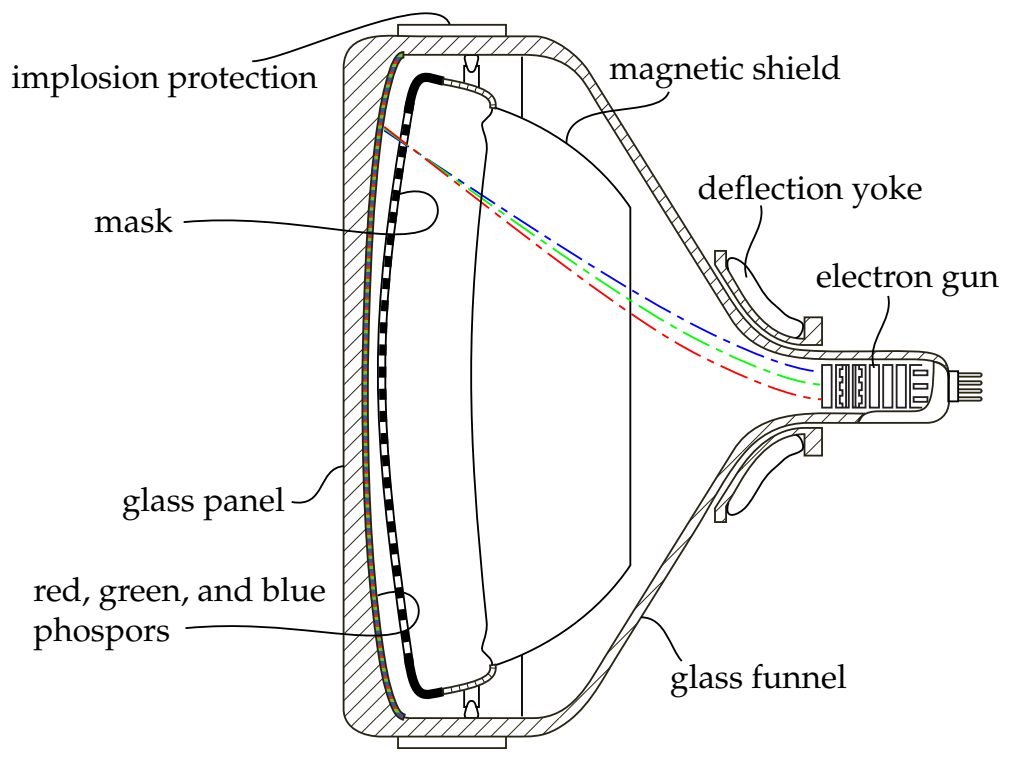

Figure 3. Section of a cathode ray tube

\section{A. The role of substitutability as a determinant of organizational choice}

A core innovation of our paper is in identifying substitutability of creative efforts $s$ as a determinant of organizational choice. The next corollary uses friendlier language to draw out this implication from proposition 1.

Corollary 1.1 (Substitutability and organizational choice) An increase in the degree of substitutability between the creative efforts of the principal and the agent (i.e., an increase in s) can lead to a change in organizational form. In case 1, as s rises from 0 to 1 the organizational form changes from the implementation form to the knowledge form and then to the control form. In case 2, the organizational form changes from the implementation form to the control form.

To investigate the empirical relevance of this corollary we present the case of the cathode ray tube (CRT). The CRT lies at the heart of colour TVs. As illustrated in figure 3, it consists of an electron gun that bombards the phosphor-coated inner surface of the glass panel, causing phosphors coloured in red, green, and blue to glow and produce a colour image (see Alig, 1999, for more details). Accurately targetting the inner surface of the glass panel with electrons is tricky. This is the job of the deflection yokes (which create a magnetic field that forces the electron beams to scan across the glass panel surface) and the 
sophisticated, pattern-forming mask (which shapes the electron beams). The surface must be accurately targeted both in terms of location (which determines the focus or vividness of the image) and in in terms of intensity (which determines the brightness of the image).

The electron gun and phosphor-coated surface sit inside a vacuum glass tube. The tube must meet three main requirements. First, it must be strong enough to withstand the vacuum pressure. Second, the front panel of the tube must have a thickness that is substantially uniform so as not to distort the image as it passes through the glass. Third, since the phosphor-coated surface sits up against the front panel, the panel must have a shape that is easily targeted by the electron gun.

In the high end of the North American CRT market, there are only eight CRT manufacturers (e.g., Sony) supplied by four glass manufacturers (e.g., Techneglass). Both the glass and CRT manufacturers routinely improve their components. Because the electronic and glass components are interdependent, changes in one component invariably require custom changes in the others. Despite the required customization of glass tubes, the relationships between glass and CRT manufacturers were both arms-length and stable throughout the 1980 and the first half of the 1990 .

In the early 1990s there was a change in the industry that might be viewed as a natural experiment. Incremental improvements in CRTs had reached the point where flat-screen displays were feasible, though expensive. The flat screen created a host of new technical problems. (For a discussion, see us patent $6,121,723$.) In particular, it compromised the strength of the glass tube (curved structures, as in domes, withstand pressure better) and also made it difficult to ensure that focus and brightness where uniform from edge to edge of the flat screen (in curved tubes the edges and the centre of the front panel are more equidistant from the electron gun). Broadly speaking, there are two solutions to these problems. First, the glass can be made thicker around the edges in order to strengthen the tube, a practice known as wedging (see, e.g., us patent 5,107,999). Wedging can be seen in the CRT of figure 3. This glass manufacturer's solution imposes heavy implementation costs on the CRT manufacturer because the variable glass thickness makes 
it even more difficult to ensure uniform focus and brightness across the front panel. The CRT manufacturer must therefore make modifications to the electron gun and the phosphor-coated surface (see, e.g., us patent 6,307,333). Alternatively, the electron gun can be designed to ensure edge-to-edge focus and brightness on a uniformly thin front panel (see, e.g., us patent 5,539,285). This CRT manufacturer's solution imposes heavy costs on the glass manufacturer because it means that the tube can only be strengthened by more fully exploiting the compressive characteristics of the glass (see, e.g., us patent $6,353,283)$. What this means is that the introduction of the new flat-screen displays sharply reduced substitutability between the creative efforts of the CRT and glass manufacturers. In the notation of our model, $s$ fell. ${ }^{18}$

According to our model, this exogenous fall in $s$ should have led to a change in organizational form. In particular, the dominant organizational form, which involved out-sourcing the design and production of the glass tube (i.e., the control form), should have given way to the knowledge-form organization or even the implementation-form organization. This is precisely what happened. The case of Sony provides a good example. Instead of approaching its traditional glass manufacturers for a solution, Sony partially integrated its operations in two ways (see Hardison, 1996). First, it initiated a joint venture with Corning-Asahi, called American Video Glass (AVG), which was mandated to design and produce a glass tube with a uniformly thin front panel. Sony's control over AVG is evident from the fact that AVG was located inside Sony's Pittsburgh production facility. The AVG arrangement thus has features of both the knowledge- and implementation-form organizations. Second, Sony continued to out-source glass tubes from its existing suppliers, such as Techneglass. This out-sourcing arrangement is essentially an implementationform organization. Thus, corollary 1.1 correctly predicts developments in the organizational form of this industry.

\footnotetext{
${ }^{18}$ All of these patents protect small incremental improvements to the glass and electronic components of CRTS. Yet the existence of these patents has not prevented each manufacturer from finding slightly different solutions and filing patent applications over its particular blueprint or implementation of a blueprint. See Levin, Klevorick, Nelson, and Winter (1987) for evidence that in most sectors firms do not regard patents as an effective means of protecting incremental innovations, but file patent applications anyway for a host of other reasons.
} 
Finally, it is worth pointing out that more traditional explanations for vertical integration are not relevant here. For one, Sony's AVG arrangement was not about concentrating different stages of the TV production process in one site: AVG was set up to supply Sony's San Diego production facility, not Sony's Pittsburgh production facility where it was located. For another, the usual hold-up explanation (e.g., Klein et al., 1978; Williamson, 1985; Hart, 1995) is not relevant here either. First, Sony and all other CRT manufacturers had a long history of ordering custom glass tubes from outside suppliers. Despite the potential for hold-up that custom tubes entail, out-sourcing of tubes was pervasive and stable throughout the 1980s and early 1990s (before flat-screen displays appeared). Second, throughout this long period, Sony bought from three of the four main glass tube suppliers and these suppliers appear to have freely applied knowledge developed for Sony to the glass tubes they supplied to Sony's competitors. (See Helper et al., 2000, for evidence that this is a common practice among suppliers in many industries.) Third, even after the introduction of flat-screen displays Sony continued to out-source glass tubes from its existing suppliers, which suggests that investment specificity did not become any more of a concern. Fourth, both the CRT and glass manufacturers' patents cited above clearly state that the introduction of flat screen displays created technical problems for which there were two types of solutions, each of which shifted the burden of implementation onto the other party. Finally, we are clearly dealing with the production of knowledge, which has more of a public-goods character than, say, a Fisher Brothers automotive body. In short, it seems that the change in organizational form had little to do with transportation costs or hold-up and everything to do with a reduction in Sony's ability to substitute its creative effort for that of its glass tube suppliers. That is, we are dealing with a reduction in $s$.

\section{B. The role of appropriability risk as a determinant of organizational choice}

Another innovation of our paper is in identifying an appropriability problem that exploits the public-goods nature of knowledge. The next corollary uses friendlier language to draw out this implication from proposition 1 . 
Corollary 1.2 (Appropriation costs and organizational choice) An increase in the cost of appropriability risk for the principal (i.e., an increase in $\alpha$ ) pushes the organizational form away from both the knowledge and control forms towards the implementation form.

To illustrate this point we return to the CRTs found in colour TVs. There is wide heterogeneity in the extent to which CRT manufacturers involve their suppliers in knowledge creation and control. For instance, Hitachi out-sources the design and production of its CRTS. Sony instead designs its own tubes, produces the key technological components, and keeps a tight control over the technical specifications of the components it out-sources. A key difference between the two manufacturers is the type of pattern-forming mask that each uses. See figure 3. Hitachi uses a fairly standard shadow mask whereas Sony uses its advanced 'Triniton' aperture-grille mask. As a result, Sony has a jump on the field and crucial knowledge to hide from manufacturers that have started producing Trinitron clones. (The Triniton patent just expired.) Given these differences in the appropriability of mask technology, our model correctly predicts that Hitachi will out-source more than Sony.

Notice once again how the choice of organizational form is very different from the usual one (e.g., Klein et al., 1978), including, most recently, Grossman and Helpman (2002). In the usual setting, there is a relationship-specific investment and one party can renegotiate for a better deal knowing that the investment is not worth anything to the other party in the absence of a deal. The solution is to integrate, possibly incurring additional governance costs. Here integration will not solve the public goods, knowledge-appropriation problem. The principal has two solutions. She may set an incentive-compatible payment that prevents the agent from trying to claim ownership of the knowledge (the $\mathrm{K}$ and $\mathrm{C}$ forms). Alternatively, the principal may choose not to involve the agent in knowledge creation (the I form). In either case, the public-goods nature of knowledge is central. 


\section{Co-existence of organizational forms}

A very different way of thinking about proposition 1 is as a statement about the coexistence of organizational forms. The idea is that if there are multiple principal-agent matches, each with an idiosyncratic characteristic $(\alpha, s)$, then we would observe the simultaneous coexistence of up to three different organizational forms. Such heterogeneity appeared in our discussion of Hitachi and Sony. In this case, the heterogeneity is induced by differences across firms in $\lambda$ and hence $\alpha$. In the section on general equilibrium we will consider the existence of multiple matches each characterized by a different $s$. We then show that in equilibrium, organizational forms co-exist.

To summarize, proposition 1 contains two novel features. It tells us how organizational forms vary with the degree of substitutability of creative efforts $(s)$ and with the risk of appropriation $(\alpha)$. It also predicts that heterogeneity in $\alpha$ or $s$ will lead to the coexistence of organizational forms.

\section{Higher appropriability risk with control}

In the next two sections we show how easy it is to extend proposition 1 in a number of interesting and empirically relevant directions. Suppose that the agent is more likely to walk away with the principal's idea if he has been delegated control over the implementation of knowledge, perhaps because control gives the agent additional tacit knowledge or credibility in court. Let $\lambda^{\prime}$ be the share of profits going to the agent in a C-form organization and let $\lambda$ continue to denote the agent's share in a K-form organization. If the risk of appropriation increases when the agent has control, then $\lambda^{\prime}$ will exceed $\lambda$ (although the model can equally accommodate the reverse).

The optimal effort levels are independent of $\lambda^{\prime}$ and $\lambda$, as can be seen from equations (7), (11) and (15). Consequently, this generalization only requires one to change $\lambda$ to $\lambda^{\prime}$ in the expression for $\mathbf{E} U_{p}^{C}$ in (16). As a result, $V_{p}^{C}$ in equation (17) becomes

$$
V_{p}^{C}=\frac{1-\lambda^{\prime}}{1-\lambda} \frac{(1+2 s)^{2}}{(1+s)(2+s)} .
$$




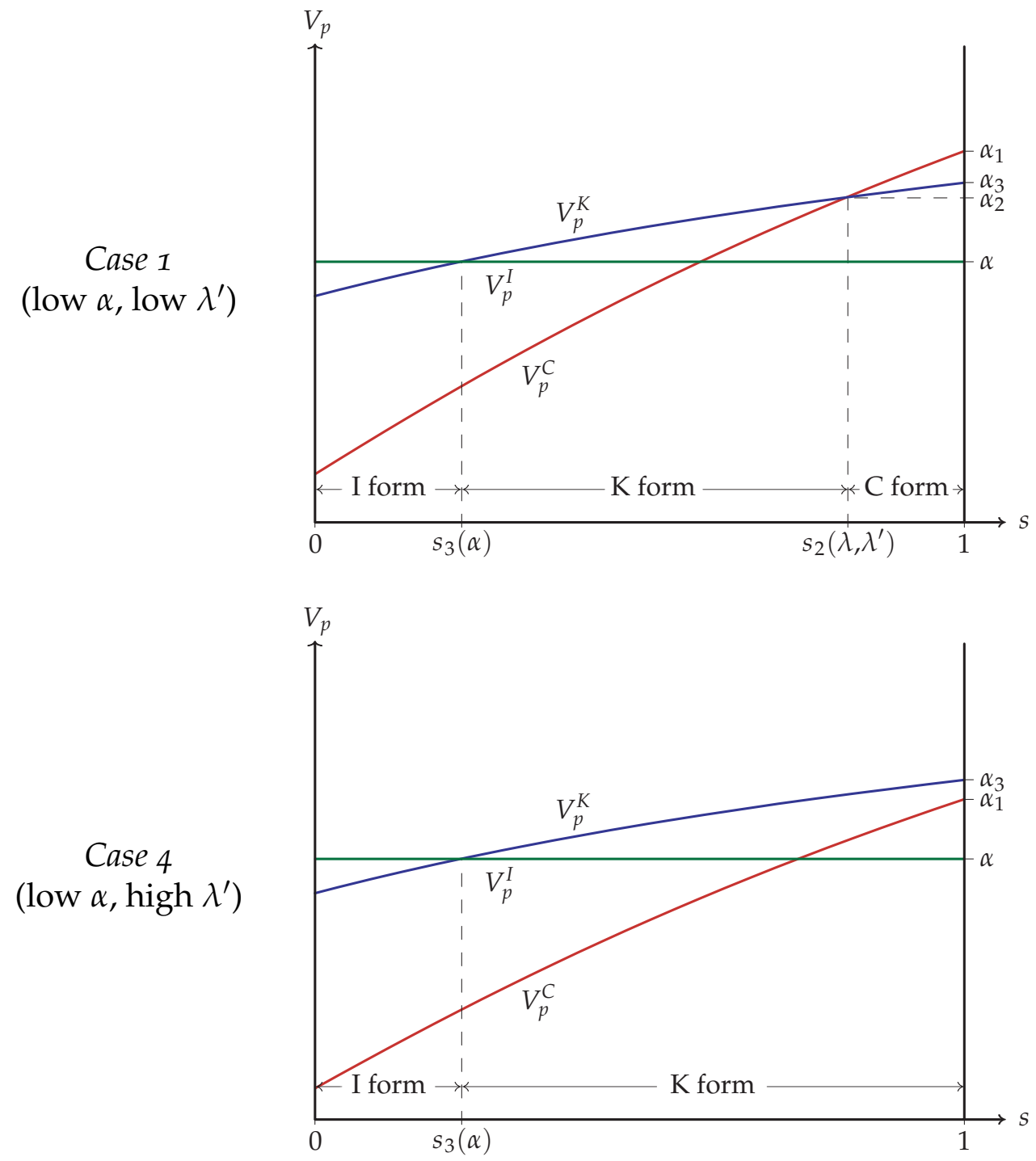

Figure 4. Co-existence of organizational forms when appropriability risk increases with control

From the discussion of figure 2, all that the introduction of $\lambda^{\prime}>\lambda$ does is to lower the $V_{p}^{C}$ curve. Consequently, the cut-off $s_{2}$ between the $\mathrm{K}$ and $\mathrm{C}$ forms, which was a constant $1 / \sqrt{2}$, becomes dependent on the appropriability parameters $\lambda^{\prime}$ and $\lambda$. This provides an additional channel through which appropriability and control interplay. The cut-off $s_{3}$ between the I and $\mathrm{K}$ forms is unchanged, while the cut-off $s_{1}$ between the I and $\mathrm{C}$ forms now also depends on $\lambda^{\prime}$ and $\lambda$. Thus, definitions 1 and 2 generalize as follows. 


\section{Definition $\mathbf{1}^{\prime}$ (Critical degrees of substitutability with $\lambda^{\prime} \neq \lambda$ )}

1. Let $s_{1}\left(\alpha, \lambda, \lambda^{\prime}\right) \equiv \frac{3 \alpha(1-\lambda)-4\left(1-\lambda^{\prime}\right)+\sqrt{\alpha(1-\lambda)\left[\alpha(1-\lambda)+12\left(1-\lambda^{\prime}\right)\right]}}{2\left[4\left(1-\lambda^{\prime}\right)-\alpha(1-\lambda)\right]}$ be the value of $s$ that equates $V_{p}^{I}=V_{p}^{C}$

2. Let $s_{2}\left(\lambda, \lambda^{\prime}\right) \equiv \frac{2\left(\lambda-\lambda^{\prime}\right)+\sqrt{(1-\lambda)\left(1-\lambda^{\prime}\right)}}{\left(1+\lambda-2 \lambda^{\prime}\right) \sqrt{2}}$ be the value of $s$ that equates $V_{p}^{K}=V_{p}^{C}$.

3. Let $s_{3}(\alpha) \equiv \frac{2(\alpha-1)}{2-\alpha}$ be the value of $s$ that equates $V_{p}^{I}=V_{p}^{K}$.

\section{Definition $2^{\prime}$ (Critical degrees of appropriability with $\lambda^{\prime} \neq \lambda$ )}

1. Let $\alpha_{1} \equiv \frac{3\left(1-\lambda^{\prime}\right)}{2(1-\lambda)}$ be the value of $\alpha$ that satisfies $s_{1}\left(\alpha, \lambda, \lambda^{\prime}\right)=1$.

2. Let $\alpha_{2} \equiv \frac{2+2 s_{2}\left(\lambda, \lambda^{\prime}\right)}{2+s_{2}\left(\lambda, \lambda^{\prime}\right)}$ be the value of $\alpha$ that satisfies $s_{2}\left(\lambda, \lambda^{\prime}\right)=s_{3}(\alpha)$ or, equivalently, $s_{2}\left(\lambda, \lambda^{\prime}\right)=s_{1}\left(\alpha, \lambda, \lambda^{\prime}\right)$.

3. Let $\alpha_{3} \equiv \frac{4}{3}$ be the value of $\alpha$ that satisfies $s_{3}(\alpha)=1$.

The consequences of this generalization for the choice of organizational form can be seen by comparing figure 2 (where $\lambda^{\prime}=\lambda$ ) with figure 4 (where $\lambda^{\prime}>\lambda$ ). Consider case 1 . Starting from $\lambda^{\prime}=\lambda$ (the top panel of figure 2), an increase in $\lambda^{\prime}$ lowers the $V_{p}^{C}$ curve (the top panel of figure 4 ). This shifts $s_{2}$, the cut-off between the $\mathrm{K}$ and $\mathrm{C}$ forms, to the right. That is, it makes C-form organizations less likely.

If one continues to increase $\lambda^{\prime}$ to the point where the $V_{p}^{C}$ curve lies everywhere below the $V_{p}^{K}$ curve (which, by equations 17 and 19 happens when $\lambda^{\prime}>1-2 \lambda$ ) then the $C$ form disappears entirely. See the bottom panel of figure 4 . In this case, matches to the left of $s_{3}$ adopt the I form while those to the right of $s_{3}$ adopt the $\mathrm{K}$ form. This case does not happen with $\lambda^{\prime}=\lambda$.

Thus, proposition 1 generalizes as follows. 
Proposition $\mathbf{1}^{\prime}$ (Co-existence of organizational forms with $\lambda^{\prime} \neq \lambda$ )

Case 1. If $\lambda^{\prime}<1-2 \lambda$ and $\alpha<\alpha_{2}$ then the principal chooses the I form whenever $s \in\left(0, s_{3}(\alpha)\right)$, the $K$ form whenever $s \in\left(s_{3}(\alpha), s_{2}\left(\lambda, \lambda^{\prime}\right)\right)$, and the $C$ form whenever $s \in\left(s_{2}\left(\lambda, \lambda^{\prime}\right), 1\right)$.

Case 2. If $\lambda^{\prime}<1-2 \lambda$ and $\alpha \in\left(\alpha_{2}, \alpha_{1}\right)$ then the principal chooses the I form whenever $s \in\left(0, s_{1}\left(\alpha, \lambda, \lambda^{\prime}\right)\right)$ and the $C$ form whenever $s \in\left(s_{1}\left(\alpha, \lambda, \lambda^{\prime}\right), 1\right)$.

Case 3. If $\lambda^{\prime}<1-2 \lambda$ and $\alpha>\alpha_{1}$ or if $\lambda^{\prime}>1-2 \lambda$ and $\alpha>\alpha_{3}$ then the principal always chooses the I form.

Case 4. If $\lambda^{\prime}>1-2 \lambda$ and $\alpha<\alpha_{3}$ then the principal chooses the I form whenever $s \in$ $\left(0, s_{3}(\alpha)\right)$, and the Korm whenever $s \in\left(s_{3}(\alpha), 1\right)$.

\section{A busier principal}

In March 2001, the Boeing Company announced it was fundamentally changing its organizational structure. Boeing had three major lines of business, including the famous commercial aircraft unit co-located with its corporate headquarters in Seattle. Faced with a flat market for commercial aircraft and limited growth potential elsewhere, Boeing's corporate management set out to identify new lines of business. At the same time, corporate managers knew that to remain competitive they needed to continue delivering incremental innovations in their existing lines of business. To achieve both ends, Boeing's corporate management decided to relinquish control over operational improvements in its existing lines of business. In particular, it promoted the three existing unit heads to chief executive officers and geographically separated the corporate headquarters from all 
three business units. ${ }^{19}$

This is yet another example of a change in organizational form that cannot be explained by the more conventional approach to organizations that emphasizes hold-up issues. It can however, be easily understood within our framework simply by introducing one additional parameter that measures how busy the principal is with other tasks. More generally, this allows us to analyze the effects of managerial overload on the involvement of subordinates in knowledge creation and control.

So far we have assumed that the principal and the agent have similar demands on their time. Let us now allow for the possibility that the principal is busier than the agent. The simplest way to do this is by assuming that the principal has $\theta$ units of time less than the agent. Then the principal's leisure is $l_{p}=\left[\left(1-e_{p}\right) s-\theta\right]$ when the agent's preferred blueprint is implemented and $l_{p}=\left(1-e_{p}-\theta\right)$ when the principal's own preferred blueprint is implemented. (Our baseline case corresponds to $\theta=0$.) The agent's leisure continues to be $l_{a}=\left(1-e_{a}\right) s$ when the principal's preferred blueprint is implemented and $l_{a}=\left(1-e_{a}\right)$ when the agent's own preferred blueprint is implemented.

When the agent is not involved in knowledge creation, the problem faced by the principal now that $\theta$ units of her time are already taken by other tasks is

$$
\max _{\left\{e_{p}\right\}} \mathbf{E} U_{p}^{I}, \quad \mathbf{E} U_{p}^{I}=\left(\pi-w_{a}^{I}\right) e_{p}\left(1-e_{p}-\theta\right)
$$

The solution to this yields the principal's equilibrium creative effort level under the I form as

$$
e_{p}^{I}=(1-\theta) / 2
$$

Note that $e_{p}^{I}$ is decreasing in $\theta$ : as the principal becomes busier with other tasks, she is less willing to exert creative effort. This lowers the probability of a blueprint being developed.

\footnotetext{
${ }^{19}$ The simultaneous announcement of these two decisions and the explanations given by Boeing's Chairman at the news conference made it clear that the relocation of Boeing's corporate headquarters (to Chicago, it was later announced) was not just about locating more centrally within the United States; it was mainly a commitment to delegating control over incremental knowledge creation. (Indeed, centrally-located Saint Louis was not even considered as a potential headquarter location because it housed Boeing's military aircraft and missile operations and Boeing's Chairman felt that having business units managers down the corridor from him would limit their initiative.) A recording of Boeing's news conference of 21 March 2001 is available from http://www. boeing.com/news/.
} 
When the agent is involved in knowledge creation, the problem faced by the principal is now

$$
\max _{\left\{e_{p}\right\}} \mathbf{E} U_{p}^{K}, \quad \mathbf{E} U_{p}^{K}=(1-\lambda) \pi\left\{e_{p}\left(1-e_{p}-\theta\right)+\left(1-e_{p}\right) e_{a}\left[\left(1-e_{p}\right) s-\theta\right]\right\}
$$

if the principal retains control, and

$$
\max _{\left\{e_{p}\right\}} \mathbf{E} U_{p}^{C}, \quad \mathbf{E} U_{p}^{C}=(1-\lambda) \pi\left\{e_{a}\left[\left(1-e_{p}\right) s-\theta\right]+\left(1-e_{a}\right) e_{p}\left(1-e_{p}-\theta\right)\right\}
$$

if control is delegated to the agent. The solutions to these yield the reaction functions of the principal under the $\mathrm{K}$ and $\mathrm{C}$ forms as

$$
e_{p}^{K}\left(e_{a}\right)=\frac{1-2 s e_{a}-\theta\left(1-e_{a}\right)}{2\left(1-s e_{a}\right)} \quad \text { and } \quad e_{p}^{C}\left(e_{a}\right)=\frac{1-(1+s) e_{a}-\theta\left(1-e_{a}\right)}{2\left(1-e_{a}\right)},
$$

respectively. The main point to note from these equations is that both $e_{p}^{K}\left(e_{a}\right)$ and $e_{p}^{C}\left(e_{a}\right)$ are decreasing in $\theta$ : as the time spent by the principal on other tasks increases, she is less willing to exert creative effort for any given level of creative effort by the agent. In other words, an increase in $\theta$ shifts down the principal's reaction functions under the $\mathrm{K}$ and $\mathrm{C}$ forms. Figure 5 illustrates this. (The downwards shift in the principal's reaction functions can be seen by comparison of figures 5 and 1.)

The agent's problem under each organizational form and the agent's reaction functions when he is involved in knowledge creation are unaffected by the fact that the principal is busier. (The relevant equations for the agent appear in section 2 above.) However, the agent is now further to the southeast along his $\mathrm{K}$ - and C-form reaction functions. The busy principal puts in less creative effort while the agent puts in more.

Thus, while there is a direct cost of work overload for the principal in terms of foregone leisure, she also enjoys a strategic benefit of over-commitment: the principal's busier schedule commits her to cutting back on creative effort, thus inducing the agent to work harder. The choice of organizational form is affected by the relative magnitude of these two effects. When there is low substitutability between the creative efforts of the principal and the agent ( $s$ is low), the direct cost of over-commitment dominates. On the other hand, when there is high substitutability between the creative efforts of the principal and the agent 


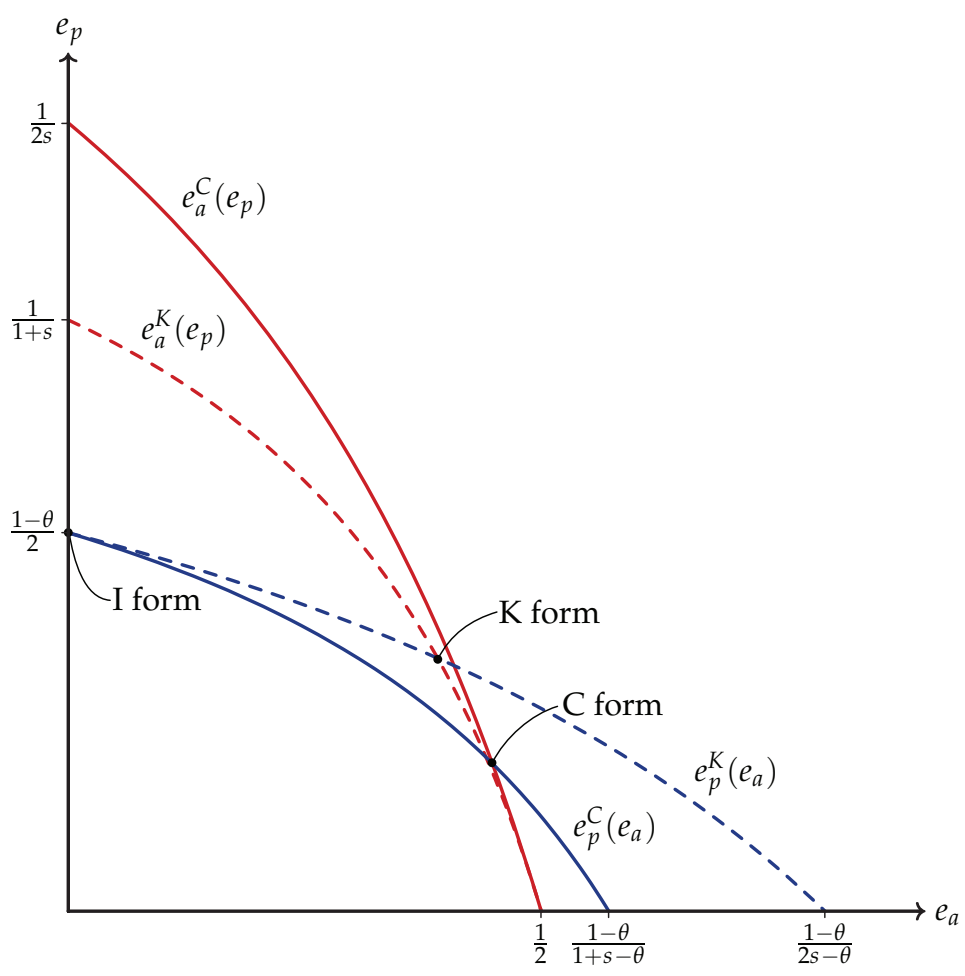

Figure 5. Creative effort reaction functions when the principal is busier

( $s$ is high), the strategic benefit of being busy dominates. To see this, consider a faculty member (a principal) with an idea for a paper. She engages a PhD student (an agent) to do at least some of the research. If the faculty member becomes involved in another activity that eats up her time (e.g., chairing the recruiting committee), how will this affect the student's involvement and the faculty member's research output? The answer will depend on the degree of substitutability between the creative efforts of the faculty member and the student. If the student's research effort is not very substitutable with the faculty member's then the student's output will be far from a finished product, the supervisor will not have enough time to finish the paper, and the project will be still-born. On the other hand, if the student's research effort is very substitutable with the faculty member's, taking on other commitments can be good for the supervisor's research productivity. It induces the student to work harder and the student's output will be so close to what the faculty member would have done that it will result in a good co-authored paper with little time involvement by the faculty member. 


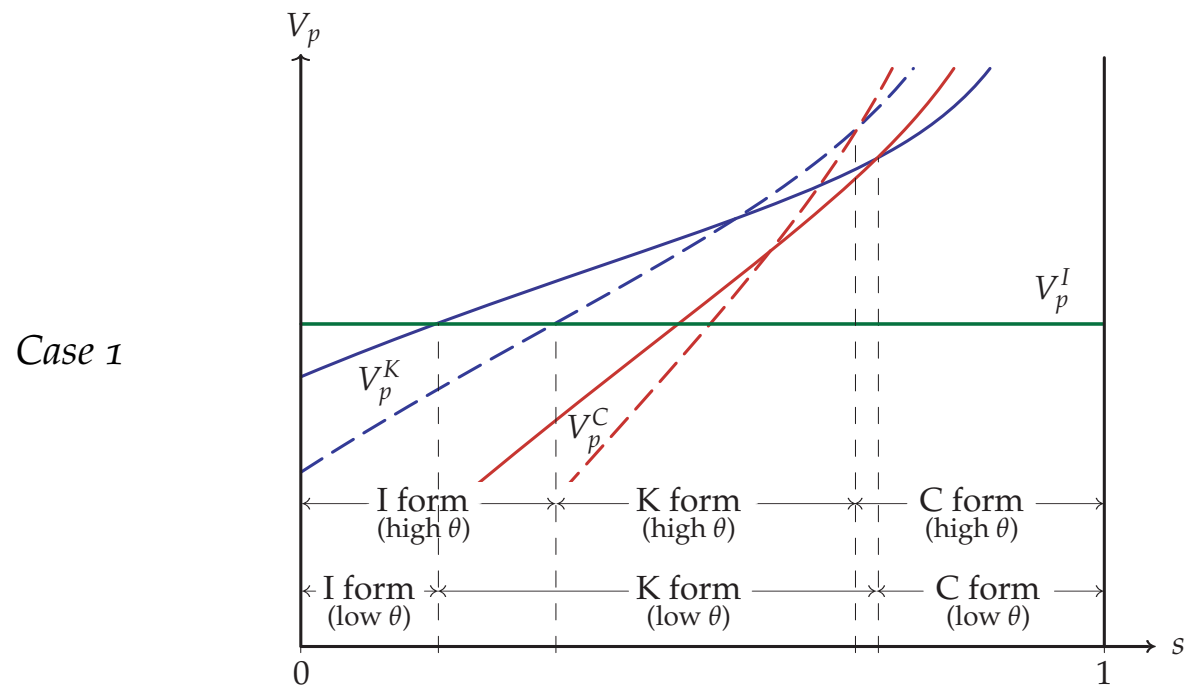

Figure 6. Co-existence of organizational forms when the principal is busier

Figure 6 graphically illustrates the issues. For low levels of substitutability (low s) the $V_{p}^{K}$ curve shifts down, reflecting the direct cost of work overload. As a result, the cut-off between the I and K forms shifts left. Simply put, if substitutability is low then the busy principal either does it herself or does not do it at all. She will not waste time on large implementation costs. For high levels of substitutability (high $s$ ) the $V_{p}^{K}$ curve shifts up, reflecting the benefit of strategic over-commitment that forces the agent to work harder. As a result, the cut-off between the $\mathrm{K}$ and $\mathrm{C}$ forms shifts right. Simply put, if substitutability is high then the busy principal delegates most aspects of the project.

The transformation of Boeing's organizational form can be seen as an example of the latter change. This interpretation fits well with Boeing's own presentation of the facts. Boeing's Chairman emphasized that the aim of promoting business unit managers and relocating the corporate headquarters was to give business unit managers "more freedom to deliver operational improvements", thus allowing its corporate managers to "focus on new business opportunities for Boeing". ${ }^{20}$ That is, the aim was to reduce $e_{p}$ and raise $e_{a}$. Thus, to continue delivering incremental product improvements (knowledge creation) in the face of greater demands on their time, Boeing's corporate managers relinquished control over knowledge creation to business unit managers. In the terminology of our

\footnotetext{
${ }^{20}$ See Boeing's news release of 21 March 2001 at http://www. boeing. com/news/.
} 
framework, Boeing's internal organization changed from the knowledge form to the control form.

\section{General Equilibrium}

We have been careful to set up the model so that its general equilibrium aspects are easy to handle. While general equilibrium interactions are not the main message of this paper, we nevertheless have several reasons for pursuing them. First and most importantly, this allows us to endogenize how profits are split between the principal and the agent under the implementation form. This in turn allows us to endogenize the key appropriability parameter $\alpha=\left(\pi-w_{a}^{I}\right) /[(1-\lambda) \pi]$. Second, general equilibrium analysis allows us to endogenize the number of principals and agents. Third, it establishes the uniqueness of equilibrium. Finally, this section shows just how easy it is to use our model for general equilibrium comparative statics, a subject we will return to in future work. To avoid over-kill, we do not work through all three cases identified in figure 2 and proposition 1. Instead, we look at the most complicated case (case 1, with all three organizational forms). The remaining cases follow trivially.

Each type of actor $i(i=p, a)$ has an alternative opportunity in the 'nine-to-five' sector, that is, a sector where workers do not exert either creative effort or implementation effort. This leaves workers in this sector with one unit of leisure. Let $w_{i}^{9-5}$ be the wage in this sector. With one unit of leisure, $w_{i}^{9-5}$ will also measure utility. Each actor must decide whether to work in the nine-to-five sector or to match. Matches are characterized by the substitutability parameter $s$. The probability of entering a match of type $s$ is described by an arbitrary but known probability density function $f(s)$ defined over $(0,1)$ and with positive mass throughout this interval. With free entry into either a match or the nine-tofive sector, utility and expected utility must be equalized across activities. Since nine-tofive sector utility is just $w_{i}^{9-5}$, perfect mobility implies

$$
w_{i}^{9-5}=\int_{0}^{s_{3}} \mathbf{E} U_{i}^{I} f(s) d s+\int_{s_{3}}^{s_{2}} \mathbf{E} U_{i}^{K} f(s) d s+\int_{s_{2}}^{1} \mathbf{E} U_{i}^{C} f(s) d s, \quad i=p, a
$$


where on the right hand side expectations are taken across different values of $s$ and hence across utilities under different organizational forms. Note that since nine-to-fivers have more leisure time, their incomes must be lower. ${ }^{21}$

We have not explained what nine-to-fivers do. While there are many options, the simplest for present purposes is an activity that does not introduce another product market. We thus treat nine-to-fivers as production line workers who are hired to produce the products described by blueprints. Further, to distinguish between principals and agents in the simplest way possible, we assume that when employed as nine-to-fivers, agents are $\phi$ times as productive as principals:

$$
w_{a}^{9-5}=\phi w_{p}^{9-5} .
$$

The incentive compatibility constraint derived in section 4 implies $0<\phi<1$.

We will need to keep track of the number of principals $L_{p}$, the number of agents $L_{a}$, the number of matches $m$, and the number of matches that successfully produce blueprints $n$. Let $\rho \equiv n / m$ be the probability that a match successfully produces a blueprint. $\rho$ is given by

$$
\begin{aligned}
\rho\left(s_{3}\right) \equiv \frac{n}{m} & =\int_{0}^{s_{3}} e_{p}^{I} f(s) \mathrm{d} s+\int_{s_{3}}^{s_{2}}\left[e_{p}^{K}+\left(1-e_{p}^{K}\right) e_{a}^{K}\right] f(s) \mathrm{d} s+\int_{s_{2}}^{1}\left[e_{a}^{C}+\left(1-e_{a}^{C}\right) e_{p}^{C}\right] f(s) \mathrm{d} s \\
& =\frac{1}{2} \int_{0}^{s_{3}} f(s) \mathrm{d} s+\frac{3}{2} \int_{s_{3}}^{1} \frac{1}{(2+s)} f(s) \mathrm{d} s,
\end{aligned}
$$

where the second line follows from substituting in the expressions for the $e_{i}^{j}$ given by equations (7), (11), and (15).

Finally, we need an expression for profits. Since there are fixed costs of developing a blueprint, firms will earn positive operational profits. Let $\mu(n)$ be a firm's mark-up i.e., (price less marginal cost)/(price). We assume only that mark-ups fall as the number of producers rises. That is, $\mathrm{d} \mu(n) / \mathrm{d} n \leqslant 0$. This is consistent with a large number of market

\footnotetext{
${ }^{21}$ It is worth noting that, besides endogenizing key variables, our approach in this section illustrates the more general point that each firms' choice of organizational form is affected by the options available to the 'marginal' principal or agent in the economy, which necessarily reflect the (general equilibrium) environment in which the firm operates. See Legros and Newman (2000).
} 
structures. $^{22}$ Each firm's revenue is a fraction $1 / n$ of total income $Y$. By the definition of $\mu(n)$, each firm's profits will be a fraction $\mu(n)$ of its revenues:

$$
\pi=\mu(n) Y / n
$$

Total income is the sum of nine-to-five incomes plus total profits $n \pi$ :

$$
Y=\left(L_{p}-m\right) w_{p}^{9-5}+\left(L_{a}-m\right) w_{a}^{9-5}+n \pi
$$

This completes our description of general equilibrium. ${ }^{23}$

Our primary interest is in endogenizing $\alpha=\left(\pi-w_{a}^{I}\right) /[(1-\lambda) \pi]$ which is equivalent to endogenizing $\omega \equiv w_{a}^{I} / \pi$. To this end, we can rewrite the equation (25) free entry conditions of the principal and agent exclusively in terms of just two unknowns, $\omega$ and the number of successful matches $n$. To do so, first note from definition 1 that $s_{2}=1 / \sqrt{2}$ and $s_{3}=2(\lambda-\omega) /(1-2 \lambda+\omega)$. Second, substitute the equation (16) expression for the $\mathbf{E} U_{p}^{j}$ into the equation (25) free entry condition for principals to obtain

$g(n, \omega)=\frac{1-\omega}{4} \int_{0}^{\frac{2(\lambda-\omega)}{1-2 \lambda+\omega}} f(s) \mathrm{d} s+\frac{1-\lambda}{2} \int_{\frac{2(\lambda-\omega)}{1-2 \lambda+\omega}}^{\frac{1}{\sqrt{2}}} \frac{1+s}{(2+s)} f(s) \mathrm{d} s+\frac{1-\lambda}{4} \int_{\frac{1}{\sqrt{2}}}^{1} \frac{(1+2 s)^{2}}{(1+s)(2+s)} f(s) \mathrm{d} s$

where $g(n, \omega)$ is simply $w_{p}^{9-5} / \pi$ expressed as a function of $n$ and $\omega$. It is straightforward to show that $\mathrm{d} g(n, \omega) / \mathrm{d} n>0$ and that $\mathrm{d} g(n, \omega) / \mathrm{d} \omega<0 .{ }^{24}$ The corresponding free entry condition for agents is

$$
g(n, \omega)=\frac{\omega}{2 \phi} \int_{0}^{\frac{2(\lambda-\omega)}{1-2 \lambda+\omega}} s f(s) \mathrm{d} s+\frac{\lambda}{4 \phi} \int_{\frac{2(\lambda-\omega)}{1-2 \lambda+\omega}}^{\frac{1}{\sqrt{2}}} \frac{(1+2 s)^{2}}{(1+s)(2+s)} f(s) \mathrm{d} s+\frac{\lambda}{2 \phi} \int_{\frac{1}{\sqrt{2}}}^{1} \frac{1+s}{(2+s)} f(s) \mathrm{d} s .
$$

${ }^{22}$ Consider two examples. If firms are monopolistic competitors producing differentiated varieties that enter consumer preferences with a constant elasticity of substitution $\sigma$, then $\mu(n)=1 / \sigma$ and $\mathrm{d} \mu(n) / \mathrm{d} n=0$. If firms are Bertrand oligopolists, again with ces product differentiation, then $\mu(n)=1 /[\sigma-(\sigma-1) / n]$ and $\mathrm{d} \mu(n) / \mathrm{d} n=-(\sigma-1) /[1+(n-1) \sigma]^{2}<0$.

${ }^{23}$ For our purposes it is sufficient to solve for the ratio $w_{p}^{9-5} / \pi$. To solve for $w_{p}^{9-5}$ and $\pi$ individually we would need an additional equation equating $w_{p}^{9-5}$ to the value of its marginal product.

${ }^{24}$ Substituting equations (26) and (29) and the definition of $\rho$ into (28) and solving for $w_{p}^{9-5} / \pi$ yields $g(n, \omega) \equiv \frac{w_{p}^{9-5}}{\pi}=\frac{[1-\mu(n)] n}{\mu(n)\left\{\left[L_{p}-n / \rho(\lambda, \omega)\right]+\phi\left[L_{a}-n / \rho(\lambda, \omega)\right]\right\}}$. Noting that, with $s_{3}=2(\lambda-\omega) /(1-2 \lambda+\omega)$, $\mathrm{d} \rho(\lambda, \omega) / \mathrm{d} \lambda<0$ and $\mathrm{d} \rho(\lambda, \omega) / \mathrm{d} \omega>0$, it is straightforward to see that $\mathrm{d} g(n, \omega) / \mathrm{d} n>0$ and $\mathrm{d} g(n, \omega) / \mathrm{d} \omega<$ 0 . Notice that, by (26), $w_{a}^{9-5} / \pi=\phi g(n, \omega)$. 


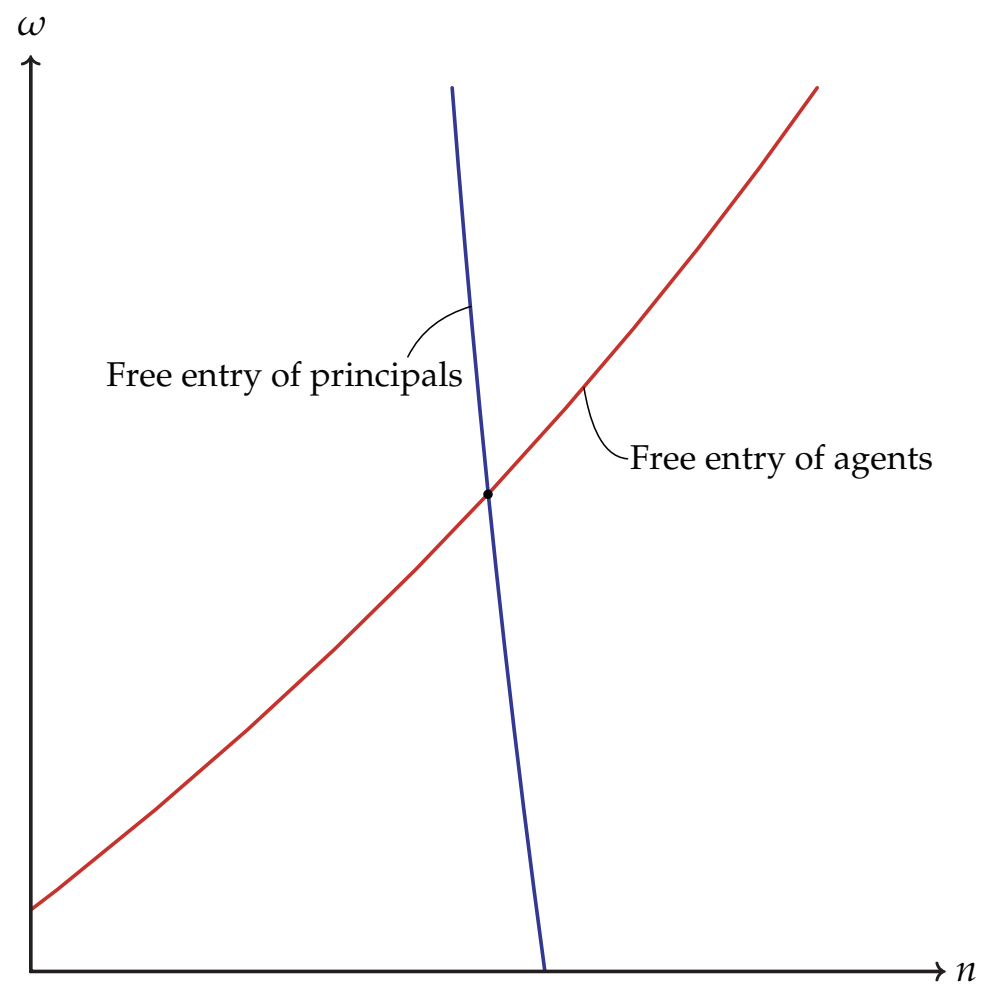

Figure 7. General equilibrium

Equations (30) and (31) jointly characterize the general equilibrium values of the number of producers $(n)$ and the share of operational profits going to the agent under the I form $(\omega)$. As illustrated in figure 7 , when drawn in $\{n, \omega\}$ space the free entry condition for agents always slopes upward and has a larger slope than the free entry condition for principals. ${ }^{25}$ Thus, the intersection of the two free entry conditions is unique as illustrated in figure 7 .

To summarize our general equilibrium derivations, let us collect our exogenous parameters in the vector $\beta=\left\{L_{p}, L_{a}, \lambda, \phi\right\}$ where $\beta \in B=\left\{(0, \infty)^{2} \times(0,1)^{2}\right\}$. The discussion leading up to figure 7 demonstrates that for each parameter vector $\beta$ there exists a unique equilibrium with $n=n(\beta)$ and $\omega=\omega(\beta)$. Since $\alpha$ is a function of $\omega$, this implies a unique $\alpha=\alpha(\beta)$. Proposition 1 with $\alpha$ set to $\alpha(\beta)$ then fully characterizes the co-existence of organizational forms in equilibrium.

\footnotetext{
${ }^{25}$ These claims about slopes follow from $\mathrm{d} g(n, \omega) / \mathrm{d} n>0, \mathrm{~d} g(n, \omega) / \mathrm{d} \omega<0$, and the fact that the righthand side of equation (30) is decreasing in $\omega$ whereas the right-hand side of equation (31) is increasing in
} $\omega$. 
Proposition 2 (General equilibrium) For each parameter vector $\beta \in B$ there exists a unique general equilibrium. The types of organizational forms that co-exist and the range of substitutability s for which each form is adopted are given by proposition 1 with the cost of appropriability $\alpha$ set to $\alpha(\beta)$.

The comparative statics discussed throughout the paper still hold in general equilibrium. We can also take these comparative statics one level deeper. For instance, we may use equations (30) and (31) to look at how the risk of appropriation $(\lambda)$ affects the number of producers $(n)$, the share of operational profits received by agents under the I form $(\omega)$, and the cut-off between organizational forms $\left(s_{3}\right)$.

So far we have taken the distribution of the substitutability parameter $f(s)$ as exogenous. Its evolution is of course of interest. The dynamic we have in mind is that the larger is the set of agents involved in knowledge creation and control, the more rapidly agents acquire the skills that principals are looking for. That is, $f(s)$ becomes skewed to the right over time. This will increase the proportion of matches that adopt the $\mathrm{K}$ and $\mathrm{C}$ forms which further reinforces the acquisition of skills. The result is a knowledge-based externality: by involving workers and subcontractors more closely in knowledge-based activities today, firms create an environment that encourages even more agent participation in knowledge-based activities tomorrow. This will have implications for growth that we hope to explore in future work.

\section{Conclusions}

Nate Rosenberg's unsung hero of economic growth is the mundane day-to-day of incremental innovation. Yet sustaining incremental innovation within a 'neo-classical firm' is difficult for reasons long ago pointed out by Arrow (1962b): the uncertainty of knowledge creation is associated with contractual incompleteness and the public-goods nature of knowledge is associated with non-appropriability. We also identified the additional problem that incremental innovation is typically embedded in complex, interdependent systems. As a result, incremental change in one component creates residual incompatibilities with other 
components. The effort needed to resolve these incompatibilities led us to our core notion of imperfect substitutability between the creative efforts of the principal and the agent.

In this environment of contractual incompleteness, non-appropriability, and imperfect substitutability, what organizational forms can firms adopt in order to mitigate the incentive problems that discourage incremental innovation? The answer, we argued, is a variety of organizational forms, each distinguished by who creates knowledge and who controls it.

Our basic analysis relies on a simple technique illustrated by figure 2. The figure shows how the risk of appropriability and the degree of substitutability together determine which of three organizational forms will appear. Focussing on substitutability, where substitutability is low the implementation-form organization appears, that is, the agent neither creates nor controls knowledge. Where substitutability is at least moderate, the principal engages the agent in knowledge creation. If in addition substitutability is sufficiently high, then the principal relinquishes control over how knowledge is used — the agent controls knowledge. We showed how our analysis explains Sony's decision to vertically integrate the production of CRTs. We also showed how easy it is to extend our analysis in any of several directions by examining Boeing's decision to vertically disintegrate its activities. In each case, we clearly identified the determinants of who creates knowledge and who controls it.

\section{References}

Aghion, Philippe and Jean Tirole. 1997. Formal and real authority in organizations. Journal of Political Economy 105(1):1-29.

Alig, R. Casanova. 1999. Cathode-ray tubes. In John G. Webster (ed.) Wiley Encyclopedia of Electrical and Electronics Engineering. New York: John Wiley \& Sons.

Anderlini, Luca and Leonardo Felli. 1994. Incomplete written contracts: Undescribable states of nature. Quarterly Journal of Economics 109(4):1085-1124.

Arrow, Kenneth J. 1962a. The economic implications of learning by doing. Review of Economic Studies 29(3):155-173. 
Arrow, Kenneth J. 1962b. Economic welfare and the allocation of resources for invention. In Richard R. Nelson (ed.) The Rate and Direction of Inventive Activity. Princeton: Princeton University Press, 609-625.

Canevazzi, Giuliano. 1992. Cathode-ray tube having improved $16 \times 9$ aspect ratio faceplate. United States Patent 5,107,999.

Duranton, Gilles and Diego Puga. 2001. Nursery cities: Urban diversity, process innovation, and the life cycle of products. American Economic Review 91(5):1454-1477.

Ghosh, Asish and Suresh T. Gulati. 2002. Implosion-resistant cathode ray tube envelope. United States Patent 6,353,283.

Grossman, Gene M. and Elhanan Helpman. 2002. Integration versus outsourcing in industry equilibrium. Quarterly Journal of Economics 117(1):85-120.

Hardison, Laura. 1996. Sony's Tv land: Vertical integration comes into focus at Pittsburgh site. Plants, Sites and Parks (July-August).

Hart, Oliver. 1995. Firms, Contracts, and Financial Structure. Oxford: Oxford University Press.

Hart, Oliver and John Moore. 1999. Foundations of incomplete contracts. Review of Economic Studies 66(1):115-138.

Helper, Susan, John Paul MacDuffie, and Charles F. Sabel. 2000. Pragmatic collaborations: Advancing knowledge while controlling opportunism. Economics of Innovation and New Technology 9(3):443-488.

Helsley, Robert W. and William C. Strange. 2002. Innovation and input sharing. Journal of Urban Economics 51(1):25-45.

Iguchi, Yukinobu and Nobuya Okano. 1996. Cathode-ray tube with electric field correction lens for improved resolution. United States Patent 5,539,285.

Klein, Benjamin, Robert G. Crawford, and Armen A. Alchian. 1978. Vertical integration, appropriable rents, and the competitive contracting process. Journal of Law and EconomiCs 21(2):297-3264.

Legros, Patrick and Andrew F. Newman. 2000. Competing for ownership. Discussion Paper 2573, Centre for Economic Policy Research.

Levin, Richard C., Alvin K. Klevorick, Richard R. Nelson, and Sidney G. Winter. 1987. Appropriating the returns from industrial research and development. Brooking Papers on Economic Activity (3):783-820.

Markusen, James R. 2001. Contracts, intellectual property rights, and multinational investment in developing countries. Journal of International Economics 53(1):189-204.

Maskin, Eric and Jean Tirole. 1999. Unforeseen contingencies and incomplete contracts. Review of Economic Studies 66(1):83-114. 
McLaren, John. 2000. 'Globalization' and vertical structure. American Economic Review 90(5):1239-1254.

National Lighting Product Information Program. 1994. Electronic ballasts: Non-dimming electronic ballasts for 4-foot and 8-foot fluorescent lamps. Specifier Reports 2(3).

Rosenberg, Nathan. 1982a. Technological interdependence in the american economy. In Inside the Black Box: Technology and Economics, chapter 3. Cambridge: Cambridge University Press, 55-80.

Rosenberg, Nathan. 1982b. Learning by using. In Inside the Black Box: Technology and Economics, chapter 6. Cambridge: Cambridge University Press, 120-140.

Sabel, Charles F. 1994. Learning by monitoring: The institutions of economic development. In Neil J. Smelser and Richard Swedberg (eds.) Handbook of Economic Sociology. Princeton: Princeton University Press, 137-165.

Segal, Ilya. 1999. Complexity and renegotiation: A foundation for incomplete contracts. Review of Economic Studies 66(1):57-82.

Sluyterman, Albertus A. S., Johannes C. A. Van Nes, and Daniel Den Engelsen. 2001. Color display device with a deflection-dependent distance between outer beams. United States Patent 6,307,333.

Sugawara, Tsunehiko, Toshihide Murakami, and Takao Kuwashima. 2000. Glass panel for a CRT having a strengthened flat face portion. United States Patent 6,121,723.

Thiébart, Patrick. 2001. Restrictive covenants in France. Annual Meeting Documents. American Bar Association Labor and Employment Law Section, Edison, NJ: Bureau of National Affairs Books.

United States Environmental Protection Agency. 1998. Lighting upgrade technologies. EPA / 430-B-95-008.

Wainwright, Milton. 1990. Miracle Cure: The Story of Penicillin and the Golden Age of Antibiotics. Cambridge, ma: Blackwell Publishers.

Williamson, Oliver E. 1985. The Economic Institutions of Capitalism: Firms, Markets, Relational Contracting. New York: Free Press. 